\title{
TURISMO Y PATRIMONIO EN CASTILLA YLEÓN: LAS CIUDADES PATRIMONIO DE LA HUMANIDAD (ÁVILA, SALAMANCA Y SEGOVIA) COMO DESTINOS TURÍSTICOS DE REFERENCIA ${ }^{1}$
}

\author{
Miguel Ángel TROITIÑO VINUESA \\ Universidad Complutense de Madrid \\ Libertad TROITIÑO TORRALBA \\ Universidad a Distancia de Madrid (UDIMA)
}

Recibido: 01/06/2010

Aceptado: 07/06/2010

\begin{abstract}
RESUMEN: La progresiva integración del patrimonio y la oferta cultural en el turismo de masas explica, en buena medida, la reciente expansión turística de los destinos patrimoniales de interior. La visita, realizada en el marco de una práctica turística de acercamiento somero al patrimonio, se focaliza en un número reducido de destinos e hitos, algo que implica riesgos de saturación y de excesiva tematización. Las Ciudades Patrimonio de la Humanidad de Castilla y León, Ávila, Salamanca y Segovia, han sido sedes de potentes eventos culturales y han efectuado una apuesta decidida por el turismo como motor de desarrollo. Son, por ello, un buen laboratorio para acercarnos a la dinámica reciente de los destinos patrimoniales y también para evaluar en qué medida la alianza estratégica entre turismo y patrimonio se ha fundamentado en una concertación de actuaciones a nivel turístico, patrimonial y urbanístico. Destaca, por un lado, el protagonismo que en este proceso han tenido los eventos culturales de proyección nacional e internacional, caso de la capitalidad europea de la cultura de Salamanca 2002 y las exposiciones del ciclo Edades del Hombre y, por otro, el papel que, en la nueva visión de la relación patrimonio-turismo y la gestión turística, han tenido los Planes de Excelencia Turística, resaltando como principal carencia la ausencia de instrumentos de gestión transversal capaces de controlar, en clave cultural, los procesos en marcha y propiciar la integración equilibrada de nuevas funciones, entre ellas la turística.
\end{abstract}

PALABRAS CLAVE: destinos patrimoniales, turismo cultural, hitos monumentales, Ávila, Salamanca, Segovia.

\footnotetext{
${ }^{1}$ Este trabajo se integra dentro del proyecto de investigación Turismo Cultural: Dinámicas recientes y estrategias de intervención en destinos patrimoniales". Ministerio de Educación y Ciencia. Plan Nacional de I+D+I (2004-2007). Referencia: SEJ2006-10898/GEOG. Departamento de Geografía Humana U.C.M (2006-2009).
} 
TOURISM AND HERITAGE IN CASTILE AND LEÓN: THE WORLD HERITAGE CITIES (ÁVILA, SALAMANCA AND SEGOVIA) AS BENCHMARK TOURIST DESTINATIONS

ABSTRACT: The gradual integration of heritage and cultural attractions into mass tourism explains to a great extent the recent growth in tourism to inland heritage sites. Undertaken within the framework of a perfunctory, tourism-oriented approach to heritage, these visits focus on a limited number of sites and architectural landmarks, a fact which carries the risk of saturation and excessive thematization. The World Heritage Cities of Castile and León, Ávila, Salamanca and Segovia have been the setting for significant cultural events, and they have now resolved firmly in favour of tourism as the driving force behind their development. They represent, therefore, good examples to help understand the recent dynamics of heritage destinations, and also to assess to what extent the strategic alliance between heritage and tourism has been based on coordinated actions at touristic, heritage and town planning levels. It is notable that, on the one hand, national and international cultural events have played a leading role in this process, for example, the European Union's designation of Salamanca as Capital of Culture in 2002, and the Ages of Man exhibitions, whilst on the other, within the framework of this new approach to the heritagetourism relationship and tourism management, Tourism Excellence Plans have also played a role, highlighting the absence of instruments for transversal management capable of monitoring, in cultural terms, the processes in motion, and encouraging the balanced integration of new functions, among them, tourism.

$\boldsymbol{K E Y}$ WORDS: heritage destinations, cultural tourism, architectural landmarks, Ávila, Salamanca, Segovia

\section{TOURISME ET PATRIMOINE EN CASTILLE-ET-LEON: LES VILLES PATRIMOINE MONDIAL DE L'UNESCO (ÁVILA, SALAMANQUE ET SEGOVIE) COMME DESTINATIONS DE REFERENCE}

$\boldsymbol{R} \boldsymbol{E} \boldsymbol{S U M E}$ : L'intégration progressive du patrimoine et de l'offre culturelle dans le tourisme de masse explique en grande partie la récente expansion de l'activité touristique des destinations culturelles d'intérieur. La visite, effectuée dans le cadre d'un stage touristique d'approche sommaire du patrimoine culturel, se focalise sur un nombre réduit de destinations et de jalons, ce qui implique un risque de saturation ou de thématisation excessive. Les Villes Patrimoine de l'Humanité de Castille-et-León: Ávila, Salamanque et Ségovie, ont organisé d'importants événements culturels et ont pris un ferme engagement en faveur du tourisme comme moteur de développement. C'est ainsi que ces villes constituent un intéressant laboratoire pour étudier la récente dynamique des destinations culturelles ainsi que pour déterminer dans quelle mesure la combinaison d'activités touristiques, patrimoniales et urbanistiques a-t-elle pu influencer l'alliance stratégique entre le tourisme et le patrimoine. Il s'agira, tout d'abord, de mettre en valeur le rôle qu'ont joué les différents événements culturels à rayonnement national et international dans ce processus, par exemple le statut de capitale européenne de Salamanque en 2002 et les expositions du cycle Las Edades del Hombre. Et d'autre part, d'étudier l'implication des Plans d'Excellence Touristique dans la nouvelle perception de la relation entre patrimoine et tourisme et celle de la gestion touristique. Pour ce faire nous soulignerons l'absence d'outils de gestion transversale capables de contrôler, d'un point de vue culturel, les processus en cours et de favoriser l'intégration équilibrée de nouvelles fonctions, notamment la fonction touristique.

MOTS-CLÉS: destinations culturelles, tourisme culturel, jalons monumentaux, Ávila, Salamanque, Segovie. 
TURISMO E PATRIMÓNIO EM CASTELA E LEÃO: AS CIDADES PATRIMÓNIO DA HUMANIDADE (ÁVILA, SALAMANCA E SEGOVIA) COMO DESTINOS TURÍSTICOS DE REFERENCIA

RESUMO: A progressiva integração do património e a oferta cultural no turismo de massas explica, em boa parte, a recente expansão turística dos destinos patrimoniais do interior. A visita, realizada no marco da prática turística de aproximação superficial ao património, focaliza-se no reduzido número de destinos e marcos, o que implica riscos de saturação e de excessiva centralização. As cidades Património da Humanidade de Castela e Leão, Ávila, Salamanca e Segovia, foram sedes de importantes eventos culturais e tem apostado decididamente pelo turismo como motor de desenvolvimento. Por isso, a experiência de estas cidades são um laboratório para nos aproximar à dinâmica atual dos destinos patrimoniais e também para avaliar como a aliança estratégica entre turismo e património fundamentou-se num concerto de atuações a nível turístico, patrimonial e urbanístico. Destaca, por um lado, a importância, que neste processo tem tido os eventos culturais de projeção nacional e internacional, como por exemplo na cidade capital europeia da cultura de Salamanca e as Exposições do ciclo Las Edades del Hombre e, por outro lado, o papel que, numa visão nova da relação patrimonial e da gestão turística, tiveram os Planes de Excelencia Turistica, realçando, como a principal carência, a ausência dos instrumentos de gestão transversal capazes de controlar, em chave cultural, os processos em andamento e propiciar uma integração equilibrada de novas funções.

PALAVRAS CHAVE: destinos patrimoniais, turismo cultural, marcos monumentais, Ávila, Salamanca, Segovia.

\section{TURISMO, PATRIMONIO Y DINÁMICAS URBANAS}

Las ciudades de Ávila, Salamanca y Segovia durante las dos últimas décadas, en el marco de un proceso de profundas transformaciones urbanas y un fuerte crecimiento del turismo llamado cultural, se han ido consolidando como destinos patrimoniales, entendiendo por tales aquellos donde el patrimonio y la oferta cultural constituyen el principal motivo de atracción para los visitantes, sean estos turistas o excursionistas. Nos interesa acercarnos a la explicación del proceso considerando no solo factores de naturaleza turística, sino también los relacionados con las dinámicas culturales, patrimoniales, urbanísticas y económicas de las ciudades y, especialmente, de sus centros históricos ( TROITIÑO VINUESA; TROITIÑO TORRALBA, 2010).

La recuperación y puesta en valor, cultural y turístico, de los conjuntos patrimoniales no está exenta de dificultades, debido, entre otras causas, a un cierto olvido de las dimensiones sociales, funcionales y paisajísticas, todo ello en un contexto urbanístico expansivo que en las tres ciudades ha significado fuertes crecimientos periféricos y pérdida de vitalidad y diversidad en sus centros históricos, especialmente en términos residenciales y comerciales. El patrimonio cultural, además de referente simbólico e identificativo de un territorio, es una parte relevante de la calidad de un sistema urbano donde la pérdida de vitalidad, la infrautilización o la excesiva presión turística no sólo pueden destruir valores sino generar desequilibrios y pesadas hipotecas de futuro. La cuestión de la 
conservación y utilización turística del patrimonio, por tanto, no debería disociarse de los cambios funcionales, sociales y urbanísticos que se producen en las ciudades y en los sistemas territoriales donde éstas se insertan. El paisaje urbano de las tres ciudades ha conocido transformaciones hasta ahora desconocidas y su realidad tiene bastante poco que ver con la existente a comienzos de los años 1980, ciudades con una estructura compacta y escasa proyección turística.

Castilla y León se caracteriza, en buena medida, por contar con un sistema patrimonial territorial (conjuntos históricos, caminos históricos, monumentos, yacimientos arqueológicos, paisajes culturales, etc.) de gran riqueza y singularidad, siendo también un territorio donde la actividad turística, con un papel bastante secundario en la economía regional a finales de la década de 1980, se ha reforzado en la actualidad y, con casi seis millones de viajeros alojados en sus establecimientos turísticos (JUNTA DE CASTILLA Y LEÓN: Boletín de Coyuntura Turística, 2010), contribuyó en 2009 con el $10 \%$ a la economía regional y, según los registros de la Tesorería General de la Seguridad Social, en 2009, generaba 68.419 puestos de trabajo. En este sentido, el turismo es considerado como un sector estratégico a nivel regional, comarcal y en los planes estratégicos urbanos, tal como señala el Plan Estratégico de Turismo de Castilla y León, 20092013 (JUNTA DE CASTILLA Y LEÓN, 2008: 5): "El sector turístico de Castilla y León ha de considerarse como un conjunto estratégico dentro de la economía regional, ejerciendo una posición de liderazgo en la creación de desarrollo, que mejore la calidad de vida de los municipios y de las personas que forman parte de esta Comunidad Autónoma".

La riqueza patrimonial regional, tanto cultural como natural, ofrece, en un contexto donde la crisis obliga replantear los parámetros sobre los que se ha fundamentado el crecimiento económico de las últimas décadas, oportunidades para contribuir a configurar nuevos modelos de desarrollo (TROITIÑO VINUESA, 2009a). El turismo visualiza la dimensión económica del patrimonio pues su conservación, promoción y puesta en valor se realiza con la finalidad explícita de materializar su riqueza en actividad económica, abriendo el debate sobre el impacto de la cultura en el turismo (OCDE, 2009). Los bienes incluidos en la Lista del Patrimonio Mundial han tenido un papel destacado en la revalorización cultural y turística de los conjuntos patrimoniales, evidenciando las contradicciones del sistema en que vivimos, pues la Lista contribuye a configurar destinos de referencia donde, luego, no es fácil controlar los procesos e impactos que el turismo desencadena (LAZZAROTTI, 2000).

Las Ciudades Patrimonio de la Humanidad de Castilla y León se han convertido en importantes focos de atracción de visitantes y su patrimonio, impulsado por el turismo, ha trascendido la dimensión cultural y se ha convertido en recurso productivo. Las razones que justifican la protección de un conjunto patrimo- 
nial, su valor cultural, singularidad y autenticidad, son las mismas por las cuales ese lugar desea ser visitado por millones de personas (SANZ, 2009). Pero, si bien el desarrollo del turismo puede contribuir a su conservación y revitalización, el incremento de los visitantes, amenaza para unos y oportunidad para otros, exige la puesta a punto de una planificación precisa y de una gestión adaptada a su capacidad de acogida (TROITIÑO VINUESA, 2009b). Para convertir el turismo en un aliado de la conservación, uno de los grandes desafíos del siglo XXI, hay que dotarse de planes de gestión de naturaleza integrada y trabajar de forma coherente y complementaria en diversos frentes para preparar los conjuntos patrimoniales y convertirlos, en sentido estricto, en destinos patrimoniales (BRITO, 2009). Sin esta visión integrada es prácticamente imposible llevar a buen puerto estrategias de conservación activa, donde las ciudades cumplan las Directrices de Gestión de la UNESCO y asuman, realmente, los compromisos que voluntariamente adquirieron al solicitar su inclusión en las Lista del Patrimonio Mundial (IAPH, 2009).

La lectura del patrimonio cultural como fuente de riqueza y motor de desarrollo abre nuevas vías de acción y, en este sentido, el Memorando y la Declaración de Viena (UNESCO, 2005) brindan la oportunidad para resituar la cuestión funcional y económica, así como la turística, en el marco del debate sobre la conservación y la gestión de las Ciudades Patrimonio de la Humanidad (TroitiÑo VinUESA, 2009c). El Plan de Turismo Español Horizonte 2020, formulado en un contexto de crecimiento, ya planteaba la necesidad de impulsar estrategias cualitativas, consensuadas con los diversos agentes sociales, para no adentrarse por el peligroso camino de la insostenibilidad que hipotecaría el desarrollo turístico futuro. Ahora, en un contexto de crisis, estos planteamientos resultan más necesarios si realmente queremos superar modelos que se han demostrado poco sostenibles. De ahí que el patrimonio cultural se identifica como una de las fortalezas de Castilla y León y, tanto desde las políticas turísticas (Plan Estratégico de Turismo 2009-2012) como desde las de patrimonio (Plan PAHIS del Patrimonio Histórico de Castilla y León 2004-2012), se apueste por su incorporación de una forma sostenible a las estrategias de desarrollo.

\subsection{Un progresivo reforzamiento del papel del turismo en políticas y es- trategias.}

El turismo, por las expectativas de negocio que despierta, ha tenido un papel destacado en los procesos de recuperación patrimonial, de dinamización económica y de transformación urbanística. Sin embargo, su inserción en los conjuntos patrimoniales no ha estado exenta de conflictividad, resultando ésta menor en las ciudades con políticas más activas y multifuncionales. Ávila, Salamanca y Segovia, no sin polémicas y dificultades (plaza del Grande en Ávila, 
Adoratrices en Salamanca, plaza del Azoguejo en Segovia, etc.) lo están afrontando de forma desigual, pero, no hay duda, que a partir de la década de 1980 en Salamanca y, algo más tarde, en Ávila y Segovia se viene realizando un considerable esfuerzo en la recuperación del patrimonio y también, aunque en menor medida, en la adecuación de los recursos culturales y conjuntos urbanos para el turismo. Para ello se han utilizado vías diversas: urbanística (planes generales y planes especiales), patrimonial (declaración de B.I.C., Patrimonio Cultural de la Humanidad, etc.) y turística (Planes de Excelencia, etc.). El proceso tiene luces y sombras pero la situación patrimonial de estas ciudades, especialmente en lo concerniente a los hitos monumentales y al espacio público, ha variado de forma significativa. El esfuerzo realizado se ha visto recompensado con una significativa mejora de su posición en el ranking turístico, evidenciando que la alianza entre turismo y patrimonio, si se maneja adecuadamente, es positiva.

La formulación y gestión de planes de Excelencia Turística ha ofrecido una oportunidad de cambio en los modelos de intervención turística (CALLE, 2006). Así, desde una perspectiva de gestión turística, se ha resaltado, en el caso de Salamanca, el esfuerzo realizado para la conformación de la llamada "ciudad turística" (HERNÁNDEZ, 2010). Los recursos y destinos patrimoniales, sin embargo, aun presentan limitaciones en su configuración y adecuación turística, así, en Ávila, sobre un total de 38 Bienes de Interés Cultural, cuatro tienen funcionalidad turística principal, siete secundaria y veinticinco incidental (TROITIÑO TORRALBA, 2010, 479).

El planeamiento urbanístico de estas ciudades, tanto en sus catálogos de protección como en la regulación de usos y actividades no siempre ha estado atento a las demandas y necesidades turísticas. Hasta comienzos de la década de 1990, cuando el turismo empieza a ganar peso en la agenda política local, no se perciben cambios significativos en los modelos de intervención turística en las ciudades. Será a fines del siglo XX cuando progresivamente se pase a ir adoptando estrategias de desarrollo urbano, más o menos explícitas, donde se empiece a considerar el turismo como un vector potencial de recuperación.

En los Proyectos Estratégicos de los Planes de Excelencia Turística de las tres ciudades se presta atención a las actuaciones de mejora del producto turístico patrimonial, en tanto que recurso primario del destino, y se trabajará con la finalidad de ampliar y diversificar la oferta turístico-patrimonial. Dentro de esta filosofía se enmarcan actuaciones emblemáticas y de éxito evidente como la puesta en valor y la adecuación para la visita turística de la muralla de Ávila (GARCÍA HERNÁNDEZ, 2004) o Ieronimus en las torres de la catedral de Salamanca. El turismo se vislumbra como un posible aliado de la recuperación urbana, propiciando que las administraciones públicas empiecen a considerarlo 
como función de recambio para los centros históricos, algo que, por otra parte, tiene riesgos, especialmente si adquiere carácter de monocultivo, evidente en calles como Reyes Católicos en Ávila, Real en Segovia o Mayor de Salamanca.

La irrupción del turismo, además de hoteles, restaurantes, comercio turístico, etc., ha propiciado múltiples oportunidades de intervención y la puesta en marcha de nuevos servicios y equipamientos, como han sido los palacios de congresos, museos, centros de interpretación, etc. En unos casos se ha recurrido a recuperar edificios de valor histórico-artístico como contenedores de estas instalaciones, en otros, se han levantado edificios de nueva planta, como el centro de recepción de visitantes de Ávila o los palacios de congresos de Salamanca y Ávila. Desde la perspectiva turística, cobran especial interés actuaciones relacionadas con la adecuación general del espacio público, iluminación de monumentos y espacios urbanos, rehabilitación de fachadas, adecuación ambiental de espacios de borde, etc. Dentro de las actuaciones de mejora del sistema local de acogida, han cobrado especial interés los proyectos de señalización turística, donde se trata de ajustar la estética de las señales al entorno patrimonial en el que se ubican, con el objetivo de minimizar impactos visuales sobre los valores paisajísticos de estos espacios (BRANDIS; DEL Río, 1998), así como los riesgos de una excesiva tematización.

En las tres últimas décadas, los centros históricos de Ávila, Salamanca y Segovia se han reforzado a nivel turístico y cultural. La cultura y el turismo se han consolidado como pilares fundamentales para la recuperación física y la dinamización funcional. Sin embargo, la multifuncionalidad, uno de los rasgos tradicionales de sus centros históricos, tiene dificultades y el desarrollo turístico no está exento de problemas y de presiones sobre la función residencial, la movilidad, la demanda de nuevas infraestructuras, etc. No está resultando sencillo reorientar la promoción y el desarrollo, tanto cultural como turístico, desde criterios de sostenibilidad.

\section{TURISMO, PATRIMONIO Y OFERTA CULTURAL: UNA ALIANZA ESTRATÉGICA PARA CASTILLA Y LEÓN.}

El estudio sobre Turismo Cultural, realizado por Turespaña en 2001, ponía de relieve la débil imagen que España tenía como destino de turismo cultural. Se estimaban en 8.500 .000 los viajeros culturales año, pero sólo el 10,6\% de los extranjeros que nos visitaba lo hacía por motivos culturales y nuestro país sólo captaba el 8\% de los viajes de los europeos por motivación cultural (TROITIÑO VINUESA; TROITIÑO TORRALBA, 2009). Entre los productos turísticos y destinos culturales señalados por los touroperadores no aparecía ninguno de Castilla y León. En las dos últimas décadas se han incorporado nuevos destinos y pro- 
ductos, tales como Salamanca, Ávila o Segovia, que han reforzado y modernizado su planta hotelera y su oferta cultural.

\subsection{Turismo cultural: un segmento clave en el despegue de Castilla y León.}

Los Informes de Perspectivas Turísticas de Exceltur vienen resaltando la creciente preferencia de los turistas por la realización de actividades culturales, junto con la expansión de viajes especializados por líneas de producto como los circuitos o las estancias de fin de semana en ciudades. Se busca diversificar la oferta de los destinos y mejorar la experiencia del visitante, ofreciéndole nuevos atractivos, valorizando y potenciando los recursos culturales. En este contexto, Castilla y León, región de interior, próxima a regiones urbanas con fuerte nivel de desarrollo (Madrid y País Vasco) se encuentra en una excelente posición, si tenemos en cuenta que, según indica el Boletín de Coyuntura Turística de Castilla y León, 2009, los dos motivos principales para visitarla son realizar recorridos turísticos $(42,4 \%)$ y salidas de fin semana $(16,2 \%)$.

En un contexto turístico expansivo - en 2007, España alcanzó la cifra récord de 59 millones de turistas- los destinos patrimoniales, a pesar del impacto negativo de los atentados del 11 septiembre de 2001 en Estados Unidos y del 11 marzo de 2004 en Madrid, han vivido unos años de importante crecimiento. Esta coyuntura, sin embargo, empezó a manifestar algún síntoma de agotamiento en 2007 y en 2008 ya tenía lugar una caída en el número de viajeros y pernoctaciones en los establecimientos hoteleros, proceso que se ha agudizado en 2009, reflejo evidente de cómo el turismo es un sector muy sensible a la crisis económica (TROITIÑO TORRALBA, 2010).

En 2008 la entrada de turistas extranjeros realizada en España por motivación cultural fue de 7.645.500, según FRONTUR, 2008; el 52,4\% de los turistas extranjeros (29,2 millones) efectuó visitas culturales. Castilla y León, en 2008, recibió del orden de 1.046.668 turistas extranjeros y de ellos el 60,2\% realizaron actividades culturales. Los españoles, en 2008, realizamos un total de 168,8 millones de viajes, 157,6 millones con destino a diferentes lugares de España y 11,2 millones al extranjero, según FAMILITUR, 2009. Los viajes por motivos culturales fueron de 12,2 millones, el 7,2\% del total de los realizados (el 66,7\% fueron a destinos españoles y el 33,3\% a destinos del extranjero). En 2008 los españoles realizaron 683.000 viajes a Castilla y León por motivos culturales, solo el 5,6\% de los realizados en España, siendo de reseñar una fuerte caída (del $-20,19 \%$ ) con respecto a 2007 (Anuario de Estadísticas Culturales, 2009), algo que no tiene una fácil explicación, salvo quizás que en ese año no se celebró ninguna exposición del ciclo Edades del Hombre. 


\subsection{Bienes Patrimonio de la Humanidad y Exposiciones de las Edades del Hombre: motores del despegue de los destinos patrimoniales.}

Castilla y León, con más de dos mil recursos patrimoniales catalogados, tiene condiciones para mejorar posiciones en el mercado nacional e internacional de turismo cultural. Trabajando en clave turística, la Fundación Encuentro recogía la existencia de un total de 6.448 recursos turísticos de naturaleza cultural, tanto material como inmaterial (HERRERO, 2003), pero además de recursos, para posicionarse turísticamente, hay que tener territorios y productos preparados turísticamente. En este sentido, no hay duda que las exposiciones Edades del Hombre desarrolladas en la región desde 1988 hasta 2010 y los bienes de la Lista del Patrimonio Mundial, caso de las ciudades y el Camino de Santiago, han tenido un papel fundamental.

Cuadro 1. Recursos Patrimoniales de Castilla y León: BIC

\begin{tabular}{|c|c|c|c|c|c|c|c|c|c|c|}
\hline & $A V$ & $B U$ & $L E$ & $P A$ & $S A$ & $S E$ & SO & $V A$ & $Z A$ & Total \\
\hline Arte rupestre $^{1}$ & 6 & 5 & 5 & 1 & 49 & 10 & 38 & & 3 & 117 \\
\hline Castillos & 18 & 140 & 34 & 20 & 35 & 11 & 85 & 28 & 15 & 386 \\
\hline Conj. etnológico & & & & & & & 1 & & 1 & 2 \\
\hline Conj. histórico & 8 & 37 & 19 & 14 & 15 & 12 & 13 & 14 & 7 & 139 \\
\hline Hórreos, pallozas(1) & & & 2 & & & & & & & 2 \\
\hline Jardín histórico & & & & & 2 & & & & & 2 \\
\hline Monumentos & 70 & 195 & 75 & 221 & 84 & 112 & 70 & 137 & 71 & 1.035 \\
\hline Paraje pintoresco & 2 & & 2 & & & 1 & & & 1 & 6 \\
\hline Rollos de justicia $^{1}$ & 10 & 38 & 3 & 14 & 5 & 3 & 12 & 6 & 1 & 92 \\
\hline Sitio histórico & & 2 & & & 2 & & 1 & 2 & & 7 \\
\hline Zona arqueológica & 7 & 16 & 11 & 10 & 15 & 5 & 18 & 10 & 14 & 212 \\
\hline Sin categoría & 1 & 3 & 2 & 18 & 3 & 2 & 2 & 1 & 1 & 33 \\
\hline Total & 122 & 436 & 153 & 298 & 210 & 156 & 240 & 198 & 114 & 2.033 \\
\hline
\end{tabular}

(1) Los elementos patrimoniales asociados a estas categorías no están declarados Bienes de Interés Cultural.

FuENTE: Registro de Bienes Inmuebles. Cultura y Patrimonio. Junta de Castilla y León. 2010

El Plan PAHIS del Patrimonio Histórico de Castilla y León, 2004-2012, con una interpretación territorializada del patrimonio cultural, apuesta por la conservación activa y entre sus objetivos específicos señala: "lograr un equilibrio entre patrimonio y actividad turística y de ocio, evitando la sobrecarga y estableciendo pautas para el uso de los bienes integrantes del Patrimonio Histórico" (p. 35).

Castilla y León posee siete bienes inscritos en la Lista del Patrimonio de la Humanidad de la UNESCO (de los 41 con que cuenta España), en 1984 se inscribe la catedral de Burgos, en 1985 las ciudades viejas de Segovia, Ávila, en 1988 la ciudad vieja de Salamanca, en 1993 el Camino de Santiago, Las Médulas en 1997 y el yacimiento de Atapuerca en el 2000. La administración regional presta atención diferenciada a estos bienes, así en el Plan PAHIS se define un plan sectorial con atención explícita a la ciudad antigua de Segovia y su 
acueducto, la ciudad antigua de Ávila y sus iglesias de extramuros y la ciudad antigua de Salamanca, recogiéndose el compromiso de establecer acuerdos con los Ayuntamientos para la implementación de planes específicos para mejorar la excelencia de los bienes, con especial atención al medio urbano en el que éstos se insertan, dimensión clave para contribuir a configurar destinos patrimoniales de excelencia.

Figura 1: Distribución territorial de los Recursos Patrimoniales de Castilla y León

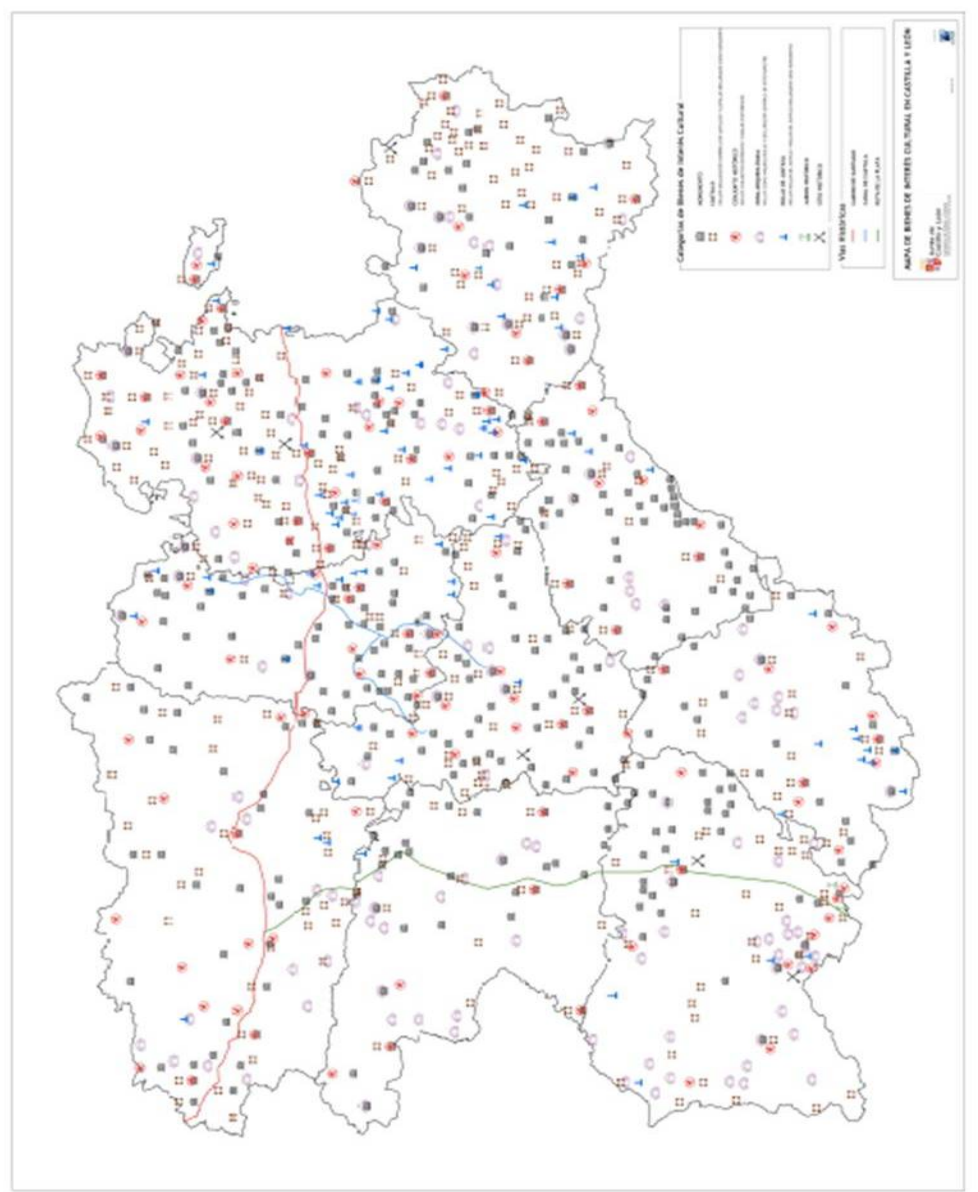

FUENTE: Plan PAHIS 2004-2012. Junta de Castilla y León. 2005.

Ávila, Segovia y Salamanca se han ido conformando como destinos turísticos, pero, si bien han ganado peso en el mercado interior, todavía no se han posicionado de forma potente en el turismo internacional (TROITIÑO VINUESA; 
TROITIÑO TORRALBA, 2008). En este sentido, señalar que Ávila en 1976 solo contaba con 688 plazas hoteleras, 1.192 en la cercana fecha de 1995 (TROITIÑO y OTROS. 1998) y, en la actualidad, cuenta con cerca de 3.000. Es así que durante los últimos años se ha realizado un considerable esfuerzo en la adecuación turística de los recursos y los destinos, en la mejora de las condiciones de accesibilidad externas (AVE, autopistas, autovías), en la ampliación de la oferta museística, en el reforzamiento de la dimensión turística de eventos culturales, especialmente evidentes con motivo de las exposiciones de la Fundación Edades del Hombre y de la capitalidad cultural europea de Salamanca 20002.

Las exposiciones de la Fundación Edades del Hombre, desde sus comienzos en Valladolid (El Arte y la Iglesia, 1988-1889) hasta la última celebrada en Soria (Paisaje Interior, 2009-2010), han tenido un papel destacado en la puesta en valor del patrimonio cultural, en el desarrollo del turismo cultural y en el despegue turístico de los destinos patrimoniales de Castilla y León. En Salamanca, la exposición el Contrapunto y su Mirada (1993-1994) permitió con algo más de 1.300.000 visitantes visualizar el potencial de desarrollo turístico de la ciudad y la rentabilidad económica de la inversión patrimonial; en Segovia, El Árbol de la Vida (2003) contribuyó a realizar esfuerzos para superar las limitaciones de ser un destino radial de Madrid; Testigos en Ávila (2004) significó la consolidación del despegue turístico.

Cuadro 2. Exposiciones de la Fundación Edades del Hombre: Indicadores

\begin{tabular}{lccrrr}
\hline \multicolumn{1}{c}{ Nombre Exposición } & Ciudad & Años & Días & Visit.s & Visit./día \\
\hline El Arte en la Iglesia & Valladolid & $1988-89$ & 163 & 1.050 .000 & 6.442 \\
Libros y Documentos & Burgos & 1990 & 180 & 500.000 & 2.778 \\
La Música en la Iglesia & León & $1991-92$ & 249 & 980.000 & 3.936 \\
El Contrapunto y su Mirada & Salamanca & $1993-94$ & 332 & 1.303 .000 & 3.921 \\
Flandes y Castilla y León & Amberes & 1995 & 86 & 95.000 & 1.105 \\
La Ciudad de Seis Pisos & Burgo de O. & 1997 & 197 & 458.000 & 2.325 \\
Memorias y Esplendores & Palencia & 1999 & 203 & 612.000 & 3.015 \\
Encrucijadas & Astorga & 2000 & 186 & 460.000 & 2.473 \\
Remembranza & Zamora & 2001 & 194 & 510.000 & 2.629 \\
Time to Hope & Nueva York & 2002 & 71 & 205.207 & 2.890 \\
El Árbol de la Vida & Segovia & 2003 & 216 & 858.977 & 3.977 \\
Testigos & Ávila & 2004 & 223 & 859.859 & 3.856 \\
Kyrios & C. Rodrigo & 2006 & 185 & 550.253 & 2.974 \\
Yo Camino & Ponferrada & 2007 & 216 & 407.040 & 1.884 \\
Paisaje Interior & Soria & $2009-10$ & 243 & 407.377 & 1.676 \\
\hline
\end{tabular}

FUENTE: Fundación Edades del Hombre. http://www.lasedades.es/

Las trece exposiciones celebradas en ciudades de Castilla y León han recibido 8.956.506 visitantes, siendo las correspondientes a las Ciudades Patrimonio de la Humanidad tres de las cuatro más visitadas. Se trata de una experiencia innovadora que al elegir para su ubicación hitos monumentales (catedrales, concate- 
drales o basílicas), localizados en conjuntos patrimoniales de primer nivel, evidencia con claridad el buen resultado de la alianza entre patrimonio y oferta cultural, el protagonismo que las catedrales tienen en la visita turística de los centros históricos (TROITIÑO VINUESA, 2008), la posibilidad de movilizar diferentes demandas de público y, también, poner de relieve como un evento cultural potente propicia la adecuación turística de los destinos (aparcamiento, señalización, peatonalizaciones, etc.), moviliza al sector empresarial y permite acortar la temporada baja.

\section{CONSOLIDACIÓN DE ÁVILA, SALAMANCA Y SEGOVIA COMO DESTINOS TURÍSTICOS.}

En el marco de la Organización de Ciudades Patrimonio Mundial se constituyó en 1993 el Grupo de Ciudades Patrimonio de la Humanidad de España, formando parte del grupo promotor Ávila, Segovia y Salamanca. En sus estatutos se señala, entre otras finalidades, la de "planificar una política turística y de difusión de imagen, que se corresponda con las ciudades miembros del grupo". El Grupo, integrado en la actualidad por trece ciudades, trabaja, en términos turísticos, en el ámbito de la promoción conjunta para afianzar su marca y cuenta, desde 2006, con un observatorio turístico (TROITIÑO VINUESA Y OTROS, 2007). El Acuerdo marco de cooperación para el desarrollo y la promoción turística del grupo Ciudades Patrimonio de la Humanidad de España, firmado con la Secretaría de Estado de Turismo en 2003, fijaba como objetivos la mejora de los servicios públicos municipales y el reforzamiento turístico, tanto a nivel nacional como internacional, la extensión de modelos integrales de gestión de la calidad y la mejora de la oferta cultural. En 2004 se puso en marcha el Club de Producto de Ciudades Patrimonio de la Humanidad de España, en el marco de una apuesta decidida por la gestión profesionalizada e integrada de los destinos (GARCÍA HERNÁNDEZ, 2007).

Cuadro 3. Indicadores turístico/patrimoniales

\begin{tabular}{lrrrrrr}
\hline & $(A)$ & $(B)$ & $(C)$ & $(D)$ & $(E)$ & $(F)$ \\
\hline Ávila & 38 & 15 & 2.684 & 11.439 & 197.892 & 322.947 \\
Salamanca & 48 & 35 & 6.919 & 25.841 & 571.587 & 947.412 \\
Segovia & 39 & 32 & 2.798 & 10.551 & 207.548 & 326.767 \\
\hline Total & 125 & 82 & 12.401 & 47.831 & 977.027 & 1.597 .126 \\
\hline
\end{tabular}

A), BIC (2006); (B), Elementos visitables (2006); (C), Plazas hoteleras (2009); (D), Capacidad salas reuniones (2009); (E), Viajeros 2009; (F), Pernoctaciones 2009

FuENTE: Observatorio Turístico del Grupo de Ciudades Patrimonio de la Humanidad de España. Universidad Complutense de Madrid. Departamento de Geografía Humana

Salamanca, Segovia y Ávila son, sin duda, un referente importante de la oferta turística de Castilla y León, destacando por sus excepcionales valores históricos, culturales y paisajísticos. Con tradición de ciudades de excursión desde las 
primeras décadas del siglo XX, su configuración como destinos turísticos de entidad es bastante reciente, pues será durante los últimos veinte años cuando el turismo se visualice con fuerza en el paisaje urbano. Los factores explicativos de esta expansión son de naturaleza diversa: aumento del consumo cultural, búsqueda de lo singular, fragmentación del tiempo de vacaciones, opción de las ciudades por el turismo como un vector de desarrollo local, estrategias de operadores turísticos, llegada de las cadenas hoteleras, etc.

El crecimiento de la afluencia de visitantes ha ido en paralelo con el incremento y modernización de la capacidad de alojamiento y con un fuerte crecimiento del número de restaurantes. Cada vez es más habitual observar como las ciudades se van incluyendo dentro de las rutas de viajes y el turismo patrimonial va ganando terreno, aunque quizás con visiones en exceso focalizadas en iconos, Ávila con la muralla, Segovia con el acueducto y el Alcázar y Salamanca con la plaza Mayor y la Universidad. La explicación de las dinámicas en el flujo de visitantes a los principales hitos patrimoniales no resulta sencilla, pues junto a los factores generales juegan otros de carácter local, no siempre evidentes en las estadísticas. Los monumentos de referencia, muralla en Ávila, universidad en Salamanca, Alcázar en Segovia, ocupan una posición de segundo nivel entre los hitos patrimoniales más visitados de España, únicamente el Alcázar se sitúa alrededor de los 500.000 visitantes año. Por otro lado, en estas ciudades existe un claro predominio del visitante español (70-80\%). El nivel de repetición de la visita se sitúa alrededor de un 30-35\%, en el caso de los visitantes individuales. Este hecho es especialmente patente en los destinos que se integran en la región turística madrileña como son los casos de Segovia o Ávila (TROITIÑO; CALLE; GARCÍA, 2002).

Cuadro 4. Visitantes de los Principales hitos monumentales

\begin{tabular}{lrrrrrrr}
\hline & \multicolumn{1}{c}{2003} & \multicolumn{1}{c}{2004} & \multicolumn{1}{c}{2005} & \multicolumn{1}{c}{2006} & \multicolumn{1}{c}{2007} & 2008 & \multicolumn{1}{c}{2009} \\
\hline Muralla (Áv) & 177.350 & 230.304 & 179.104 & 185.934 & 201.753 & 163.565 & 162.855 \\
Catedral (Áv) & s.d. & s.d. & s.d. & 94.437 & 124.134 & 142.295 & 130.003 \\
Escuelas Mayores (Sa) & 164.136 & 151.938 & 139.536 & 159.015 & 151.386 & 147.244 & (obras) \\
Exp. Ieronimus (Sa) & 11.538 & 136.491 & 144.373 & 148.153 & 144.651 & 143.184 & 140.085 \\
Alcázar (Se)) & 541.825 & 504.076 & 497.973 & 504.438 & 510.036 & 492.963 & 478.006 \\
Catedral (Se) & s.d. & s.d. & s.d. & 242.269 & 215.298 & 215.816 & 207.002 \\
\hline Total & 994.849 & 1.022 .809 & 960.986 & 1.334 .246 & 1.347 .258 & 1.305 .067 & 1.117 .951 \\
\hline FuENTE: Observatorio Turístico del Grupo de Ciudades Patrimonio de la Humanidad de España. Univer- \\
sidad Complutense de Madrid. Departamento de Geografía Humana.
\end{tabular}

Ávila, Segovia y, en menor medida Salamanca, se consolidan como destinos con un importante peso del excursionismo y el porcentaje de turistas ronda, a nivel general, el 30\%. La duración de la estancia raramente llega a las dos noches. Otro de los aspectos que caracterizan el perfil turístico de estas ciudades es la focalización de la visita sobre unos ejes muy limitados del entramado cultural urbano. Los visitantes acuden poco a museos y monumentos, salvo a los 
muy relevantes, y se dedican fundamentalmente a pasear, comprar, comer o tomar algo en un contexto de ocio, especialmente en el caso de los que repiten visita.

\section{1. Ávila: el Plan de Excelencia Turística y la exposición de Edades del Hombre claves en el despegue como destino patrimonial.}

Ávila, ciudad declarada conjunto histórico en fecha tardía, 1982, e incluida en la Lista del Patrimonio de la Humanidad en 1985, a comienzos de la última década del siglo XX era una pequeña ciudad, 47.000 habitantes, donde el turismo tenía una presencia limitada. Su oferta de alojamientos en 1995 era de 1.258 plazas, predominando las categorías de tipo medio; la mitad de los establecimientos, los que habían introducido nuevos conceptos empresariales y los que habían elegido edificios antiguos rehabilitados para desarrollar su actividad, se localizaban en el sector oriental del recinto intramuros, en la zona de mayor densidad monumental (TROITIÑO VINUESA y OTROS, 1998).

La ciudad se caracterizaba por su precaria adecuación como destino turístico y los hitos monumentales (muralla, catedral, San Vicente, convento de Santa Teresa, etc.) servían, con frecuencia, para ocultar el valor del conjunto y focalizar la visita. Las actuaciones de recuperación del patrimonio eran pocas y la cultura de la rehabilitación residencial y del espacio público tenía dificultades para implantarse. El Plan Especial del Conjunto Histórico-Artístico, 1998, planteaba entre sus finalidades, además de la protección de los edificios catalogados, asegurar la accesibilidad rodada y peatonal al recinto amurallado y reducir el tráfico de vehículos, priorizando al peatón en la zona comercial y monumental.

No existía una estrategia turística explícita, las infraestructuras de gestión eran débiles y las acciones iban poco más allá de la promoción y la edición de folletos turísticos. Madrid era el principal centro emisor y remisor de visitantes, existían problemas de accesibilidad externa y de movilidad interna, sin embargo el turismo empezaba a verse con buenos ojos, pues permitía contrarrestar el relativo estancamiento de otras ramas de actividad (VILLAR, 1999), especialmente en el centro histórico. Los visitantes de la ciudad, un número reducido de turistas y más excursionistas, se cifraban entre los 400.000-500.000 al año.

La confluencia de un abanico de factores favorables, políticos, urbanísticos, patrimoniales y económicos, $\mathrm{y}$, especialmente, un protagonismo decidido de la administración municipal posibilitan un salto cualitativo en el proceso de conformación del destino (GARCÍA HERNÁNDEZ, 2004). En el marco de los planteamientos del Plan Integral de Calidad del Turismo Español (PICTE), se desarrolla el Plan de Excelencia Turística, 2000-2003, que contará con un órgano de 
gestión específico y, en el marco del Anteproyecto Estratégico del Plan de Excelencia, trabajará por dar coherencia a la política turística municipal.

La puesta en marcha del Plan de Excelencia Turística en el año 2000, aunque con un presupuesto limitado, del orden de cuatro millones de euros, supuso un punto de inflexión en la forma de pensar y abordar la gestión del turismo. Sus objetivos prioritarios eran dotar a la ciudad de unas adecuadas infraestructuras de gestión y posicionarla como destino competitivo en el mercado del turismo cultural de interior. Las líneas temáticas de actuación se centraron alrededor de cuatro ejes: mejora del recurso/producto turístico patrimonial, modernización del sistema de acogida local, comunicación turística en destino y otras actuaciones (formación, recursos humanos, convenios, etc.).

En términos urbanísticos y patrimoniales era imprescindible, avanzando sobre planteamientos de recuperación puntual de edificios monumentales, preparar elementos y zonas clave del patrimonio abulense para su correcta articulación turística. En relación con la creación de productos turísticos es de reseñar la construcción del Centro de Interpretación del Misticismo, concebido para resaltar las figuras del misticismo asociadas al pasado de Ávila (San Juan de la Cruz, Santa Teresa de Jesús...) y contribuir a renovar y articular la presentación del patrimonio urbano vinculado con ese eje temático.

La recuperación y puesta en valor del patrimonio ha sido uno de los grandes desafíos a los que se han tenido que enfrentar las ciudades históricas castellanas en las últimas décadas. Para ello, en una ciudad con un elevado número de hitos patrimoniales que habían ido perdiendo funcionalidad (palacios, murallas, iglesias, conventos, etc.), era imprescindible encontrar alternativas funcionales en los ámbitos de la administración, la educación, la cultura o el turismo. A intervenciones antiguas, como el museo provincial en la Casa de los Deanes, el parador nacional en el palacio de Juan de Henao, el hotel del palacio Valderrábanos o la Cámara de Comercio en la casa del regidor Antonio Navarra, se irán incorporando otras como el Servicio de cultura de la Junta de Castilla y León en el palacio de Bracamonte, la Delegación territorial de la Junta en el convento de Santa Ana, el hotel palacio de los Velada, el auditorio municipal en el convento de San Francisco, el Centro de interpretación de los vettones en el palacio de los Guzmanes o el Centro cultural de Caja Ávila en el palacio de los Serrano, Archivo provincial en la cárcel vieja, etc.

Por sus dimensiones urbanísticas, patrimoniales y turísticas destaca el complejo programa de apertura a la visita turística de diversos tramos de la Muralla. Tras las obras de consolidación, recuperación y adecuación, realizadas con el apoyo de las diversas administraciones públicas y de Caja Madrid, la apertura a la visita se convertirá en el proyecto estrella del Plan de Excelencia Turística, al 
incorporar: articulación de la oferta, profesionalización de los servicios turísticos, proyecto expositivo y nuevas formas de presentación del patrimonio (GARCÍA HERNÁNDEZ, 2004). Desde su apertura se ha convertido en un monumento-eje, clave para impulsar una estrategia turística urbana global, al propiciar una nueva lectura y presentación del patrimonio cultural de la ciudad, siendo, además, un gran atractivo para la visita como evidencia que en 2003 ya recibiese 158.657 visitantes. En la actualidad cuenta con cuatro tramos abiertos (Alcázar, Carnicerías, Ronda Vieja y Puente Adaja) y un recorrido de $1.530 \mathrm{~m}$., estando en marcha los proyectos de acondicionamiento de los tramos de Puente Adaja-Puerta de la Santa y Puerta de la Santa-Puerta del Rastro, con financiación del Ministerio de Fomento. El proceso de puesta en valor, patrimonial y turístico, evidencia, por un lado, la dimensión estratégica de la complementariedad entre recuperación patrimonial y turismo y, por otro, la complejidad del proceso, al requerir de concertación interadministrativa y complementariedad entre acciones y actuaciones de signo diverso.

La recuperación y mejora urbana se ha orientado a potenciar los valores monumentales del casco histórico y mejorar la calidad del destino. Las actuaciones desarrolladas (peatonalizaciones, rehabilitación, aparcamientos, adecuación de espacios públicos, etc.), si bien han evidenciado la importancia del efecto demostración, también han servido para poner de relieve la necesidad de herramientas de coordinación de mayor potencia, caso del Plan de Gestión del Centro Histórico, actualmente en elaboración. La mejora del sistema de acogida local han sido objeto de especial atención, para ello se ha centrado los esfuerzos en dos acciones prioritarias: la construcción del Centro de Recepción de Visitantes, en el marco de las actuaciones orientadas a renovar y cualificar el entorno de la basílica de San Vicente, y la mejora de la presentación de la ciudad a través de la implantación de señalización turística, monumental y hotelera.

La oferta cultural tradicionalmente estaba escasamente conectada con la demanda turística, aunque alguna iniciativa, caso de la exposición Castillo Interior, dedicada a Santa Teresa, celebrada en la catedral e impulsada por la Fundación de Estudios Místicos, recibió del orden de 250.000 visitantes. En este sentido, la exposición Testigos sirvió, de alguna manera, para visualizar el acierto de las políticas emprendidas. Ávila acogió en 2004 la exposición Testigos, duodécima edición de las exposiciones montadas por la Fundación Las Edades del Hombre, un acontecimiento cultural/religioso que contribuyó a posicionar Ávila como destino de turismo interior (TROITIÑO VINUESA; TROITIÑO TORRALBA, 2009). Por la exposición, de entrada gratuita, pasaron 859.859 personas entre el 4 de mayo y el 13 de diciembre de 2004, agosto fue el mes que más visitantes recibió (155.149). El promedio diario se situó en 4.236 personas, 
siendo 5.903 la media registrada en los días de fines de semana y festivos y 3.377 la media de los días entre semana.

Los 136.550 visitantes con reserva previa se organizaron en un total de 8.097 grupos de visita. La capacidad de movilización de colectivos sociales diversos fue muy alta, destacando los escolares $(17,14 \%)$, las parroquias $(16,93 \%)$, las asociaciones culturales $(14,59 \%)$, las asociaciones religiosas $(8,35 \%)$, los grupos de la tercera edad (7\%), las asociaciones de vecinos $(5,59 \%)$ y, ya con valores inferiores al 5\%, las agencias, los guías, particulares, instituciones o empresas. Las procedencias de los visitantes evidencia el protagonismo del factor proximidad, así el 43,32\% proceden de Castilla y León, el 29,10\% de Madrid y el 4,45\% de Castilla-La Mancha, siendo bajas las procedencias de Comunidades Autónomas como Andalucía (2,12\%), País Vasco (1,33\%) o Cataluña (0,31\%).

Cuadro 5. Evolución de viajeros y pernoctaciones en hoteles

\begin{tabular}{ccrrrrrr}
\hline Años & (1) & Ávila & Salamanca & Segovia & Ávila & Salamanca & Segovia \\
\hline 2003 & NA & 165.590 & 341.059 & 139.286 & 249.675 & 572.475 & 211.417 \\
& EX & 29.467 & 129.099 & 43.452 & 39.809 & 208.430 & 63.502 \\
& TO & 195.057 & 470.158 & 182.738 & 289.484 & 780.905 & 274.919 \\
\hline 2004 & NA & 194.801 & 388.072 & 128.605 & 288.753 & 669.494 & 191.729 \\
& EX & 27.338 & 141.744 & 39.896 & 42.499 & 223.308 & 60.671 \\
& TO & 222.139 & 529.816 & 168.501 & 331.252 & 892.802 & 252.400 \\
\hline 2005 & NA & 196.159 & 416.179 & 128.969 & 300.967 & 701.570 & 190.524 \\
& EX & 29.467 & 137.829 & 31.569 & 48.373 & 221.004 & 47.563 \\
& TO & 225.626 & 554.008 & 160.538 & 349.340 & 922.574 & 238.088 \\
\hline 2006 & NA & 195.688 & 438.168 & 152.226 & 312.160 & 764.485 & 227.860 \\
& EX & 30.345 & 143.889 & 34.814 & 48.636 & 241.463 & 52.835 \\
& TO & 226.033 & 582.057 & 187.040 & 360.796 & 1.005 .948 & 280.695 \\
\hline 2007 & NA & 198.396 & 435.965 & 179.598 & 320.845 & 758.950 & 279.592 \\
& EX & 37.074 & 140.924 & 40.207 & 55.188 & 237.181 & 66.423 \\
& TO & 235.470 & 576.889 & 219.805 & 376.032 & 996.131 & 346.015 \\
\hline 2008 & NA & 181.379 & 446.148 & 174.831 & 298.351 & 753.284 & 277.608 \\
& EX & 35.984 & 144.440 & 36.100 & 56.189 & 231.384 & 61.028 \\
& TO & 217.363 & 590.588 & 210.931 & 354.540 & 984.668 & 338.636 \\
\hline 2009 & NA & 168.918 & 432.263 & 173.175 & 279.230 & 725.161 & 269.703 \\
& EX & 28.974 & 139.324 & 34.373 & 43.717 & 222.251 & 57.064 \\
& TO & 197.892 & 571.587 & 207.548 & 322.947 & 947.412 & 326.767 \\
\hline
\end{tabular}

(1): NA, Nacionales; EX, Extranjeros; TO, Total

FuENTE: Observatorio Turístico del Grupo de Ciudades Patrimonio de la Humanidad de España. Universidad Complutense de Madrid. Departamento de Geografía Humana

Las motivaciones de la visita fueron de naturaleza diversa: el 32,60\% señalaron "el gusto por el arte", el 20,90\% por razones turísticas, el 20,74\% por razones de tipo religioso/cultural y el 15,96\% simplemente por curiosidad. Los resultados de la encuesta a los visitantes de Ávila, realizada entre mayo y noviembre de 2004 , mostraron que el $92,97 \%$ de los turistas y excursionistas en- 
cuestados la habían visitado. La exposición constituyó el motivo principal de la visita Ávila para buena parte de los visitantes que llegaron durante esos meses a la ciudad (39\%) y un motivo secundario o complementario para un $18,74 \%$ más. El nivel de repetición de la visita fue muy alto, 39,45\% y alcanzó el $69,57 \%$ entre los visitantes de proximidad, lo que confirma la influencia que los eventos culturales tienen sobre la renovación del interés por la visita a destinos culturales. La exposición Testigos cuya función cultural/religiosa se cubrió con éxito, a juzgar tanto de los responsables de la Fundación Edades del Hombre como de los visitantes, también resultó exitosa en términos turísticos pues sirvió para que Ávila incrementara el número de visitantes en cerca de un $40 \%$.

La dinámica turística de Ávila, tras el boom de 2004, ha entrado en una fase normalidad manteniendo ligeras tasas de crecimiento en viajeros y pernoctaciones hasta 2007, para en 2008 y, fundamentalmente en 2009, evidenciar con fuerza, al igual que la mayor parte de los destinos del GCPHE (TROITIÑO TORRALBA, 2010), los efectos de la crisis, disminuyendo los viajeros y pernoctaciones en establecimientos hoteleros en casi un $9 \%$. El turismo extranjero tiene, todavía, una limitada presencia, del orden del 15\%, y predominan claramente los visitantes de proximidad.

También se intenta captar nuevas demandas como es el caso del turismo de congresos y reuniones, un segmento cuyas perspectivas de crecimiento no son muy favorables. En abril de 2009, en el espacio del antiguo mercado de ganados, abrió sus puertas el Centro Municipal de Congresos y Exposiciones "Lienzo Norte", con capacidad para 3.050 personas y $8.000 \mathrm{~m}^{2}$ de espacio para exposiciones, instalaciones que tiene ante sí el reto de desarrollar actividades y competir con ciudades como Madrid o Salamanca, todo ello en una ciudad que, a pesar del fuerte crecimiento urbanístico que ha conocido en los últimos años, solo cuenta con unos 63.000 habitantes.

El turismo y la cultura continúan siendo aliados indispensables para proseguir un proceso de recuperación patrimonial de la ciudad vieja y su entorno, donde quizás se haya primado en exceso las intervenciones en el patrimonio monumental que han implicado cambios no siempre positivos en términos sociales, funcionales y paisajísticos (ÁLVAREZ, 2009). La reciente puesta en marcha del Área de Rehabilitación Integrada del Centro Histórico, con una inversión prevista de 22,5 millones de euros entre 2006 y 2011, puede contribuir a reforzar la función residencial de un espacio que en la zona intramuros no llega a los 4.000 habitantes, del orden del 5\% de la población de la ciudad, con espacios centrales con síntomas evidentes de degradación como las calles de Vallespín y Caballeros. 
Las instalaciones y servicios culturales han servido, sin duda, para recuperar edificios singulares y aportar cierta vitalidad a espacios que la estaban perdiendo. Las iniciativas recientes, como es el caso del Archivo Histórico Municipal y Centro Documental del Patrimonio Mundial en el palacio de los Verdugo, o en avanzado desarrollo, como el Centro de Gestión de Depósitos del Prado, en el palacio de los Águila, o el museo de la ciudad y sede de la colección Caprotti, en la mansión de los Superunda, junto a ámbitos patrimoniales infrautilizados o ruinosos (palacio Polentinos, palacio Núñez Vela, palacio de los Sufraga, convento de las Gordillas, etc.), evidencian que aún queda camino por recorrer. Sin embargo hay que ser cautos y evitar, al igual que puede ocurrir con los hoteles y restaurantes, riesgos de una excesiva tematización.

\subsection{Salamanca: la Capitalidad Europea de la Cultura como referente en el proceso de articulación y modernización turística.}

Salamanca, a lo largo de las dos últimas décadas, se ha consolidado como un destino patrimonial competitivo dentro del Grupo de Ciudades Patrimonio de la Humanidad de España. En términos turísticos, el éxito se relaciona con el reforzamiento que el turismo ha adquirido como política pública, la innovación en la creación de nuevos productos, la implicación de la iniciativa privada y la configuración de nuevas estructuras organizativas (HERNÁNDEZ, 2010).

En este proceso, más allá de su potencia patrimonial e identidad diferenciada como ciudad universitaria, han tenido un papel destacado su inclusión en la Lista del Patrimonio de la Humanidad, 1987, y la exposición El Contrapunto y su Mirada de la Fundación Edades del Hombre, 1993-1994, que recibió 1.300.000 visitantes, el máximo de las celebradas hasta la fecha, y, fundamentalmente, la capital europea de la cultura de 2002, que permitió dar un salto cualitativo en la preparación de la ciudad como destino patrimonial y propició la llegada de una cifra de visitantes que se situó entre los 2.100 .000 y los 2.200 .000 (TROITIÑO VINUESA y OTROS, 2003a).

El Plan de Excelencia Turística, 2001-2004, tuvo un papel destacado dado que su Plan Estratégico planteó, de forma innovadora, la relación entre patrimonio y turismo, en el marco de la denominada "construcción de la ciudad turística", donde se apuesta por la modernización de la gestión (AYUNTAMIENTO DE SALAMANCA, 2001). Los esfuerzos en la protección -Plan Especial de Protección y Reforma Interior del Recinto Universitario y Zona Histórico Artística, 1987- y de recuperación del patrimonio urbano, por un lado, y la inclusión de la ciudad antigua en la Lista del Patrimonio de la Humanidad, por otro, propiciaron que el patrimonio adquiriese una posición central en la construcción del destino. La nominación de Salamanca como capital europea de la cultura (1988) ayudará, en mayor o menor medida, a un acercamiento entre políticas patrimo- 
niales, urbanísticas, culturales y turísticas. Así, la preparación de "Salamanca 2002" influyó muy positivamente en la recuperación física y funcional de un número considerable de recursos patrimoniales, así como en la creación de nuevas infraestructuras turísticas y culturales, reforzando una estrategia de recuperación patrimonial donde la ciudad había sido pionera en España en la década de 1980 (TROITIÑO VINUESA, 1992). La situación favorable, creada entorno a la capitalidad, propició la construcción y rehabilitación de establecimientos hosteleros y servicios de ocio, se abrieron al público siete nuevos hoteles, con casi 900 plazas (Salamanca Plaza, Abba Fonseca, convento San Esteban, Fábrica de Harinas el Sur, etc.), se favoreció la modernización del sector, con la llegada de las cadenas hoteleras y se construyó el primer hotel de cinco estrellas, se alcanzaron 97 establecimientos con un total de 4.780 plazas.

La preparación de la ciudad para la capitalidad implicó un amplio programa de intervenciones, dentro de un ambicioso plan de dotación de infraestructuras. Entre las que tuvieron un mayor impacto urbanístico destacan: la recuperación y rehabilitación de la antigua Prisión Provincial como Centro de Arte de Salamanca; la construcción del Centro de Artes Escénicas; la rehabilitación de la primera central eléctrica de la ciudad como Museo de Historia de la Automoción; la construcción del pabellón Multiusos; la recuperación y rehabilitación del teatro Liceo; la rehabilitación del archivo de la Guerra Civil; rehabilitación del colegio de Santo Domingo como sala de exposiciones y centro cultural; rehabilitación del patio de la Escuelas Menores de la Universidad; creación de un espacio museístico permanente en la Casa de la Caridad, sede de la filmoteca de Castilla y León; rehabilitación del mercado de San Juan; rehabilitación del convento de San Esteban; intervención en la hospedería de Fonseca para adecuarla como centro cultural y de formación continua; recreación museográfica de los restos del antiguo convento de San Vicente; recuperación de los aljibes del antiguo parque de bomberos como Museo del Comercio y la Industria.

La oferta cultural organizada por el Consorcio Salamanca 2002 (Ayuntamiento de Salamanca, Diputación de Salamanca, Junta de Castilla y León, Ministerio de Educación, Cultura y Deporte, Universidad de Salamanca y Caja Duero) contó con 1.101 actividades, 306 de pago y 795 gratuitas, a las que asistieron 1.927.444 personas, desarrolladas en 26 espacios culturales diferentes; la exposición de Rodin registró 280.000 visitantes. Aprovechando la capitalidad, desde diferentes instituciones y empresas, se organizaron actos culturales de naturaleza diversa.

El Plan de Excelencia Turística apostó, de forma decidida, por la apertura de los interiores patrimoniales y una de sus actuaciones emblemáticas fue la adecuación de las torres medievales de la catedral. Ieronimus, en colaboración con el cabildo de la catedral y dentro del Plan Director, es un excelente ejemplo de 
concertación que implica recuperar un espacio para la visita pública; desde su apertura en 2002 ha recibido más de un millón de visitantes.

La capitalidad cultural 2002 tuvo un importante impacto turístico, entre 2.100.000-2.200.000 visitantes, sin contar los movimientos pendulares del área de influencia de la ciudad; en temporada alta y días de máxima afluencia se llegaron a alcanzar los 12.000 visitantes diarios. El número de consultas en las oficinas de información turística se duplicó, los viajeros alojados en establecimientos hoteleros crecieron en un $15 \%$ y los registros de algunos museos y monumentos aumentaron un 50\%. "Salamanca 2002" creó una marca de amplia difusión y proyección que situó a la ciudad en el imaginario de un elevado número de personas, prologando su estela en 2003 y años posteriores.

Los visitantes en viaje individual constituyeron la fórmula de viaje dominante, un $75-80 \%$, los de grupo entre el 20-25\%. De los visitantes en grupo, el $47 \%$ fueron de turismo social, el $25 \%$ son escolares y el 28\% grupos de carácter comercial. Los visitantes nacionales fueron claramente mayoritarios, entre el 70 y $80 \%$, predominando los procedentes de Castilla y León y la Comunidad de Madrid. Entre los extranjeros, predominaron franceses, portugueses, alemanes y británicos. Los visitantes de proximidad y los extranjeros se distribuyeron de una forma bastante homogénea a lo largo del año, con dos picos en marzo y agosto; los visitantes del resto de España se concentraron fundamentalmente en los meses de verano y períodos festivos vinculados con puentes. La mayor parte de los visitantes, del orden del 70\%, fueron turistas que pernoctaron en la ciudad o su área de influencia, un rasgo diferencial con respecto a Segovia y Ávila donde los excursionistas tienen mayor presencia, predominando las estancias cortas, 1,7 días. El grueso de los visitantes tenía un alto nivel educativo, 56,10\% con estudios universitarios y, en consonancia, estaban trabajando en estratos superiores de la pirámide laboral.

En relación al uso turístico de la ciudad y de sus recursos patrimoniales es de señalar que, al igual que ocurre en otras ciudades, la visita tipo se focalizó en el entorno de la Plaza Mayor, catedrales y Universidad. El ranking de popularidad turística lo encabezó la catedral, con el 74\% de los visitantes individuales y el $98 \%$ de los de grupo. De los más de 2.100 .000 visitantes, sólo 268.271 entraron al edifico histórico de la Universidad (entrada de pago) y únicamente $57.355 \mathrm{al}$ museo Provincial. El visitante medio se inclinó más por el paseo y el disfrute de un ambiente agradable y de alto valor patrimonial que por la visita a monumentos, que en ocasiones ya había visitado puesto que el $45 \%$ de los individuales repetía visita.

La capitalidad cultural podría hacer pensar en el predominio del "visitante ilustrado", sin embargo el grueso de las personas encuestadas tenía una imagen 
turística bastante simplificada de la ciudad, en relación con la Universidad (96,22\%), capitalidad cultural $(95,93 \%)$, ciudad Patrimonio de la Humanidad $(63,10 \%)$ y el ambiente nocturno y de marcha de los estudiantes $(59,51 \%)$. En función de ello, la motivación principal para visitarla durante 2002 fue la de "conocer la ciudad en general" (61,59\%), visitar a familiares y amigos $(12,11 \%)$, pasar el día (6\%) y sólo el 5,49\% declaró como motivo principal del desplazamiento la asistencia a los eventos del Salamanca 2002. El 69,85\% de los encuestados indicaba que tomó en consideración Salamanca 2002 a la hora de tomar la decisión de viajar a la ciudad; para el 25,64\% fue el factor desencadenante de su decisión, para el $27 \%$ un factor más y para el 17\% influyó sólo un poco.

Para el Consejo de Europa, la capitalidad europea de la cultura debe significar el apoyo incondicional a la sensibilización y accesibilidad al patrimonio inmueble, el desarrollo de un turismo cultural de calidad e innovador, la gestión duradera del patrimonio cultural y, también, una relación estable entre el patrimonio cultural y el desarrollo urbanístico de la ciudad. En este sentido, Salamanca 2002 sirvió, sobre todo, para estimular la política cultural de la ciudad, así como para solventar carencias en las infraestructuras. Se crearon del orden de 25 nuevos espacios culturales, a partir de la construcción de nuevos inmuebles o de la rehabilitación de edificios históricos.

La valoración de información, señalización turística de la ciudad por parte de los visitantes fue bastante positiva, una media de 3,76 sobre 5 . No obstante, se señalaron ciertos aspectos críticos en relación con los servicios de información, precios de hoteles y restaurantes y zonas de aparcamiento. El gasto medio diario por visitante rondó los 60 euros (69 entre los turistas y 33 entre los excursionistas), estimándose el gasto turístico directo en destino en 123 millones de euros (TROITIÑO VINUESA y OTROS, 2003b). El impacto económico de la capitalidad cultural, considerando efectos directos, indirectos e inducidos, se ha estimado en 882.342.844 euros, de los cuales 278.844.583 corresponden al gasto cultural y 120.933.177 al gasto dotacional (HERRERO y OTROS, 2004).

La capitalidad cultural evidenció la necesidad de dotarse de nuevas infraestructuras de gestión y en 2003 se crea la sociedad Turismo y Comunicación de Salamanca que propicia el desarrollo de las estrategias impulsadas desde el Plan de Excelencia Turística. La industria turística se consolida, moderniza y cualifica y, en 2009, las plazas en hoteles de cuatro y cinco estrellas superan las 4.000. 'Salamanca Convention Bureau', 'Salamanca Film Commission' y 'Salamanca Ciudad del Español' se orientan a captar nuevas demandas y desestacionalizar el destino. 
Las consultas en la oficina municipal de turismo pasaron de 119.901 en el año 2000 a 286.610 en 2002, para en los años siguientes situarse alrededor de las 200.000 , efecto de la resaca de la capitalidad, e iniciar un nuevo crecimiento en 2006, alcanzando un máximo de 310.874 en 2007 y luego volver a caer en 2008 y, especialmente 2009 (289.150), por el impacto de la crisis económica. La cifra de viajeros alojados en establecimientos hoteleros pasó de 470.158 en 2003 a 582.057 en 2006, para conocer un ligero descenso, $0,9 \%$, en 2007 y en 2008 recuperarse alcanzando los 590.588, explicable en relación con los actos conmemorativos de la Guerra de la Independencia, pues en ese año los destinos patrimoniales ya empiezan a sufrir los efectos de la crisis económica (OBSERVATORIO TURÍSTICO DEL GCPHE, 2010); en 2009 ya se refleja el efecto de la crisis con una caída del $3,2 \%$, bastante inferior a la media nacional y también a la media de las ciudades del GCPHE. El turismo nacional sigue siendo mayoritario, el $72,5 \%$ de los viajeros alojados en establecimientos hoteleros en 2003 y el $75,6 \%$ en 2009 , evidenciando lo difícil que resulta ocupar un papel destacado entre los destinos culturales europeos.

\subsection{Segovia: un clásico destino de excursión que persigue singularidad en su oferta cultural y paisajística.}

Segovia, ciudad media y tradicional lugar de excursión de los madrileños, durante las dos últimas décadas viene esforzándose por consolidarse como destino patrimonial, tratando de aprovechar la posición geoestratégica de la proximidad a Madrid y las mejoras en la accesibilidad (autopista y AVE). Esta ciudad, al igual que Ávila y Salamanca, cuenta con un potente patrimonio monumental (39 BIC), urbanístico (3 conjuntos históricos) y paisajístico (casco antiguo, arrabales históricos, valles del Eresma y Clamores, etc.), así como una creciente oferta museística y cultural. El plano guía de Turismo de Segovia recoge 71 elementos patrimoniales, sin embargo solo 20 elementos tienen regulada la entrada (TROITIÑO VINUESA y OTROS, 2009: 3). Sobre un total de 32 BIC (2007) tenían funcionalidad turística principal 4 , secundaria 4 e incidental 24 (TROITIÑO TORRALBA, 2009: 479), evidenciando las limitaciones de la adecuación turística de los recursos patrimoniales.

Desde la declaración del recinto amurallado de Segovia como Monumento Histórico Artístico en 1941 a las actuales Área de Rehabilitación del Centro Histórico de la Judería (MARTín, 2010) y + Patrimonio, Programa de Puesta en Valor Turístico del Patrimonio, hay todo un rosario de planes y programas (patrimoniales, urbanísticos y turísticos), así como de proyectos e intervenciones que han tratado de recuperar y poner en valor, primero cultural y luego turístico, un potente, valioso, singular y atractivo patrimonio, tal como se reconoce con la inclusión de la ciudad vieja de Segovia y su Acueducto en la Lista del 
Patrimonio Cultural de la Humanidad la UNESCO en 1985. En esta ya larga secuencia planificadora y de intervenciones, no exenta de bloqueos y tensiones (hotel Acueducto, aparcamiento del paseo del Salón, edificios cuesta San Juan, protección de vistas, etc.), se ponen de relieve los efectos negativos de una visión patrimonial parcelada y fragmentada de la ciudad histórica, así como olvidos importantes en relación a cuestiones sociales y funcionales, tal como puede ser la turística. Catalogar y proteger el patrimonio son necesarios pero la dinámica reciente evidencia que no es suficiente para garantizar su conservación.

El Acueducto de Segovia se declara monumento nacional en 1884 y en 1941 se extiende la declaración de Monumento Nacional a la totalidad del recinto amurallado, incorporando unas innovadoras referencias a la protección de vistas, tomando como referencias el Alcázar, las torres de San Justo y Salvador y la plaza de la Canaleja (VELASCO, 2009). Si bien durante el franquismo la protección del paisaje, una de las claves de la identidad geográfica de Segovia y recurso para la atracción de visitantes, tiene poca operatividad, especialmente en los arrabales históricos con posibilidades de rentabilización urbanística, como fueron los barrios de San Millán, Santa Eulalia y, en menor medida, San Lorenzo. Las dificultades del emplazamiento de la ciudad vieja, un espigón calizo entre los ríos Eresma y Clamores, junto con el débil crecimiento demográfico y la pervivencia de una ciudad compacta permitieron que, a comienzos de la década de 1980, el recinto intramuros siguiese siendo el ámbito central de la ciudad y conservase una importante diversidad funcional y social, aunque ya se deja sentir cierta presión del excursionismo y de la hostelería, fundamentalmente en el eje Acueducto-Calle Real-Plaza Mayor-Catedral-Alcázar.

El Plan General de Ordenación Urbana de 1984, si bien incorpora la catalogación patrimonial y señala la necesidad de prestar atención a la conservación del paisaje, evidencia contradicciones entre las medidas de protección del patrimonio edificado y la pervivencia de la centralidad y la multifuncionalidad (Álvarez MoRA, 1999). Sin pretender aquí efectuar una revisión crítica del planeamiento urbanístico segoviano, nos interesa resaltar que la visión troceada y parcelada de la ciudad histórica (recinto intramuros, arrabales históricos, cinturones de los ríos Eresma y Clamores, etc.) ha resultado muy negativa, tanto desde el punto de vista de la preservación patrimonial y paisajística como de la adecuación de la ciudad histórica para las nuevas demandas y necesidades turísticas.

El amplio listado de planeamiento existente -Plan Especial del Recinto Amurallado, Planes Especiales de los Arrabales Históricos, Plan Especial de Protección Histórico Artística y Reforma Interior del Casco Antiguo Extramuros, Plan Parcial Especial de El Salvador Plaza Oriental, Plan Especial de Protección Histórico Artística y del Paisaje y Reforma Interior del barrio de San Lorenzo, Plan 
Especial de Protección Histórico Artístico y Reforma Interior de San Antonio El Real y Cuarteles, Plan Especial del Cinturón Verde y Plan especial de Protección Histórico Artística del Paisaje y Reforma Interior del Valle del Eresma y San Marcos- (VELASCO, 2009), ha resultado complejo y poco fructífero, tal como se señala en el informe sobre aplicación en Segovia de la Convención sobre Patrimonio Mundial (ICOMOS, 2004). Se evidencia, tanto por ámbitos de actuación como por temáticas (protección del patrimonio histórico artístico y del paisaje, reforma, remodelación, zonas verdes, etc.) y objetivos, lo difícil que resulta gestionar una ciudad histórica de la complejidad urbanística y patrimonial de Segovia, fundamentalmente en una coyuntura en la que se están produciendo cambios de gran calado en la estructura general de la ciudad y especialmente en los contenidos sociales y funcionales de la ciudad histórica.

En la trayectoria recorrida se pone de relieve que los instrumentos con los que se gobierna la ciudad, fundamentalmente urbanísticos y patrimoniales, no son suficientes para hacer frente a cuestiones tan relevantes como el progresivo debilitamiento de las funciones residenciales y comerciales, la paulatina minoración de funciones como la religiosa, la presión del turismo, la desaparición progresiva de las actividades fabriles y de los cultivos en las huertas en los valles del Eresma y Clamores. Las piezas del mosaico paisajístico han ido cambiando de función y no siempre se ha sabido interpretar el sentido los cambios ni, algo aún más importante, dotarse de instrumentos adecuados para acompañarlos $\mathrm{y}$ orientarlos. En esta línea, en el Informe sobre Estado de Conservación de Bienes Inscritos en la Lista de Patrimonio Mundial se señala: "se podría decir que se ha llegado al límite de tolerancia máxima. El riesgo de traspasarlo es grave, por lo que deben tomarse medidas para evitar que la ciudad pierda los valores por los que se incluyó en la Lista del Patrimonio Mundial" (ICOMOS, 2004: 21).

El Plan General de Ordenación Urbana de 2005, preocupado por la cuestión de las grandes infraestructuras y de los potentes desarrollos urbanísticos, si bien reconoce el papel del paisaje como componente de la calidad ambiental, su carácter de recurso de calidad y su fragilidad, no introduce planteamientos innovadores en relación con la visión integrada y el gobierno de la ciudad histórica. En relación con esta cuestión el mencionado informe sobre Estado de Conservación del Bien resaltaba "el entorno paisajístico del bien está amenazado por un desarrollo urbanístico inadecuado que degrada algunas visuales hacia y desde el bien declarado. Es cierto que Segovia es una de las ciudades históricas españolas que mejor ha preservado la relación paisajística en torno a la colina en la que se levanta la ciudad vieja; no obstante, las presiones urbanísticas son muy fuertes y no debe cejarse en el mantenimiento de esta circunstancia" (ICOMOS, 2004: 15). 
El Plan Especial de las Áreas Históricas (PEAHI) contempla las cuestiones de protección de espacios libres, preservación de vistas y conservación del paisaje pero tampoco articula mecanismos que permitan afrontar de forma coordinada cuestiones urbanísticas, paisajísticas, sociales y turísticas. El ARICH de la Judería y el Programa de Puesta en Valor Turístico del Patrimonio Histórico (muralla, cementerio judío, patrimonio industrial hidráulico, Acueducto) evidencia una voluntad de cambio de rumbo que, al menos en relación con la multifuncionalidad del centro histórico y la adecuación del patrimonio para la visita pública, pueden resultar positivos.

Potencia y diversidad de la oferta patrimonial, junto con una coyuntura turística expansiva desde comienzo de 1990 a 2007, explican un progresivo reforzamiento del peso del turismo en la política y la economía urbana. La ciudad ha contado tradicionalmente con una sólida oferta de restaurantes, localizados fundamentalmente en el recinto intramuros y sus entornos, pero será en las dos últimas décadas cuando modernice y consolide una importante planta hotelera, así de 1.225 plazas en 1989 pasará a 1.851 en 2003 y casi 2.800 en la actualidad.

El protagonismo que el turismo ha ido adquiriendo en la vida de la ciudad ha llevado, especialmente en la última década, a un cambio substancial en el modelo de planificación y gestión del turismo. En este proceso, el primer y gran aglutinador fue el Plan de Excelencia Turística (2000-2003) que con presupuesto limitado, poco más de cuatro millones de euros, se convierte en motor de cambio tanto en las formas de presentar el patrimonio como de gestionar el turismo (ICN-ARTEA, 2000). Una visión estratégica de las relaciones e interdependencias entre ciudad, turismo y patrimonio, llevan a plantear, por un lado, acciones de recuperación y cualificación urbana (rehabilitación, muralla y paseo de ronda, plaza oriental como puerta de acogida, cinturones verdes, movilidad y aparcamiento) y, por otro, la mejora y modernización del producto turístico (mejoras en la oferta patrimonial, señalización, gastronomía, oferta cultural, centro de visitantes, etc.).

En estos años, junto a acciones focalizadas en los hitos patrimoniales (Acueducto, Alcázar, Catedral...), se ha trabajado en el entendimiento del paisaje como valor patrimonial y recurso turístico y, también, mediante una diversificada e innovadora oferta cultural (Titirimundi, Hay Festival, MUCES, Festival Internacional de Segovia, etc.), por ampliar el ámbito, generalmente muy restringido (eje Acueducto- Calle Real- Plaza Mayor- Alcázar), de la "ciudad turística". Uno de los proyectos estrella del Plan de Excelencia Turística ha sido la adecuación del itinerario peatonal paisajístico "El Balcón de la Mirada", orientado a configurar un recurso patrimonial, el paisaje, como producto. El limitado éxito turístico de esta iniciativa evidencia que no resulta fácil cambiar las lógicas y prácticas turísticas de los visitantes que, generalmente, se conforman con un re- 
corrido rápido y superficial por los ámbitos patrimoniales más clásicos y formalizados

El Plan de Excelencia Turística desencadenó un proceso de cambio que era difícil gestionar con las estructuras tradicionales (concejalía de Turismo, patronato...) y en 2004 se constituyó la Empresa Municipal de Turismo, asumiendo la gestión turística de la ciudad con el compromiso de convertir a Segovia en un destino referente en cuanto a calidad de los servicios, diversificar la oferta de productos para superar la idea de "Segovia ciudad visitable en unas horas" y sensibilizar a los ciudadanos hacia los valores del patrimonio cultural y favorecer su comprensión del fenómeno turístico (TURISMO DE SEGOVIA, 2008).

Segovia cuenta con 51 establecimientos y 2.798 plazas hoteleras (2009), con presencia de grandes hoteles, generalmente en la periferia urbana (Parador, Mesón Cándido...), algunos de ellos en edificios de valor patrimonial rehabilitados (Monasterio de San Antonio El Real), ubicándose en el centro histórico los de pequeño y mediano tamaño. La oferta de restauración es sólida, 115 establecimientos y del orden de 15.000 plazas, el $60 \%$ en el recinto intramuros y los arrabales históricos. En general, en un casco histórico como el segoviano, con un aceptable grado de diversidad funcional, los usos turísticos van reforzando su presencia, especialmente en el eje Acueducto-Alcázar, en torno del Acueducto y Fernández Ladreda.

La profesionalización de la gestión turística ha permitido diversificar la oferta de servicios y productos turísticos (centro de recepción de visitantes del Acueducto, visitas guiadas, bus turístico, bono turístico, bono de pequeños museos, etc.). El turismo de negocios busca abrirse camino, aunque con dificultades por la proximidad de Madrid y la competencia de ciudades próximas (Ávila, Salamanca...), cuenta con 22 equipamientos y 10.551 plazas en salas de reuniones; también se ha reforzado el turismo idiomático con la oferta de cursos de español para extranjeros de Turismo de Segovia.

La ciudad, a la clásica oferta patrimonial (39 BIC) y museística (10 museos), ha incorporado, tal como hemos señalado, potentes eventos culturales como Titirimundi o Hay Festival, junto con otros de menor entidad, necesarios para reforzar la vitalidad del centro histórico y la imagen cultural del destino. Entre los eventos culturales de mayor proyección turística de los últimos años destaca la exposición El Árbol de la Vida de la Fundación Edades del Hombre en 2003, que recibió 858.977 visitantes. Existe una apuesta pública y privada por el turismo y la cultura como motores de desarrollo, tal como se evidencia en el Plan Estratégico y la candidatura de la ciudad a la capitalidad europea de la cultura 2016. 
Segovia, ciertamente, ha reforzado de forma significativa su planta hotelera, sin embargo, al igual que ocurre en otros destinos de la región turística de Madrid, el grueso del millón de visitantes que se estima recibe la ciudad al año son excursionistas. En efecto, en 2009 sólo 207.548 viajeros pernoctaron en los alojamientos hoteleros, poco más del $20 \%$ de los visitantes, predominando, al igual que ocurre en la mayor parte de las Ciudades Patrimonio de la Humanidad de España (TROITIÑO VINUESA y OTROS, 2010), el turista nacional, un $83,4 \%$ frente al $16,6 \%$ de extranjeros. La dinámica en la llegada de turistas en la última década tiene ritmos de tipo pendular, en función de coyunturas internas (exposición Edades del Hombre) y externas (atentados de 2001 en Estados Unidos y de 2004 en Madrid), siendo de reseñar que, por primera vez, en 2007 se supera la cifra doscientos mil (219.805) y las 376.032 pernoctaciones; en 2008 y 2009 se deja sentir, aunque con menor fuerza que en otros destinos, el impacto negativo de la crisis económica, con caídas del 4,04\% en 2008 y de sólo el 2,60\% en 2009 , siendo casi el doble el descenso del turismo internacional que el nacional. El ranking de turistas extranjeros está encabezado por Estados Unidos, Francia, Reino Unido, Alemania, Italia y Portugal.

El desarrollo turístico de Segovia en los últimos años se debe fundamentalmente a una coyuntura muy expansiva del turismo interior. En 2009 los servicios de información gestionados por Turismo de Segovia atendieron 331.619 consultas, de las cuales $61,94 \%$ correspondieron a nacionales y el $38,06 \%$ a extranjeros; este alto porcentaje de extranjeros, más del doble de los que se alojan en establecimientos hoteleros, se explica por el peso del excursionismo, el menor nivel de repetición de visita y el carácter de la ciudad como destino radial de Madrid, algo que se ha reforzado con la llegada del AVE en 2008. El grueso de los turistas y excursionistas nacionales son de proximidad, fundamentalmente de Madrid (18-20\%) y de Castilla y León (7-8\%), siendo de resaltar que buena parte de los visitantes de los territorios más distantes llegan a Segovia en el marco de una excursión radial desde su destino principal, generalmente Madrid.

El fuerte peso del excursionismo y la corta duración de la estancia de los turistas (1,6 noches), tanto nacionales como extranjeros, explica que durante la visita, en un contexto de ocio, se pasee por la ciudad intramuros y, en menor medida, por los arrabales históricos y los tramos de los valles de los ríos Eresma y Clamores acondicionados para la visita pública. Mientras que los visitantes del Alcázar, uno de los monumentos más visitados de España (TROITIÑO VINUESA; TROITIÑO TORRALBA, 2010), se sitúan alrededor de los 500.000, la catedral se encuentra alrededor de los 200.000 y a distancia muy significativa se sitúan los museos, el más visitado, y el nuevo Museo Esteban Vicente recibe del orden de 25.000 visitantes. 
El análisis de la evolución de los visitantes al Alcázar, hito patrimonial y referente turístico de la ciudad, refleja, por un lado, la dinámica turística de Segovia $\mathrm{y}$, por otro, las problemáticas relacionadas con la focalización de la visita, en hitos y espacios, así como las limitaciones del modelo vigente en la presentación y gestión de los destinos patrimoniales. La dinámica expansiva de la última década del siglo XX se refleja en un incremento sostenido en el número de visitantes, 452.500 en 1995 y 559.000 en el año 2000, máximo desde que se disponen de registros estadísticos. En el siglo XX tiene lugar una dinámica pendular que refleja, con claridad, el impacto de fenómenos de índole político, cultural y económico, así ocurre con la crisis en relación con los atentados de Nueva York y en 2002 el número de visitantes se sitúa en 506.367; el fuerte incremento en 2003 (541.825 visitantes) evidencia el efecto inducido por la exposición de Edades del Hombre; en 2004 el impacto negativo de los atentados de Madrid (493.758 visitantes), para, tras incrementos en los tres años siguientes, 510.036 visitantes en 2007, evidenciar los efectos negativos de la actual crisis económica, 478.006 visitantes en 2009, la cifra más baja desde 1996. La dinámica de la visita refleja, también, otras realidades a considerar, así mientras la ciudad crece en número de visitantes, en restaurantes, planta hotelera y salas de reuniones, no se incrementa el número de visitantes a monumentos y museos.

Figura 2: Evolución del número de visitantes del Alcázar de Segovia. 19952009

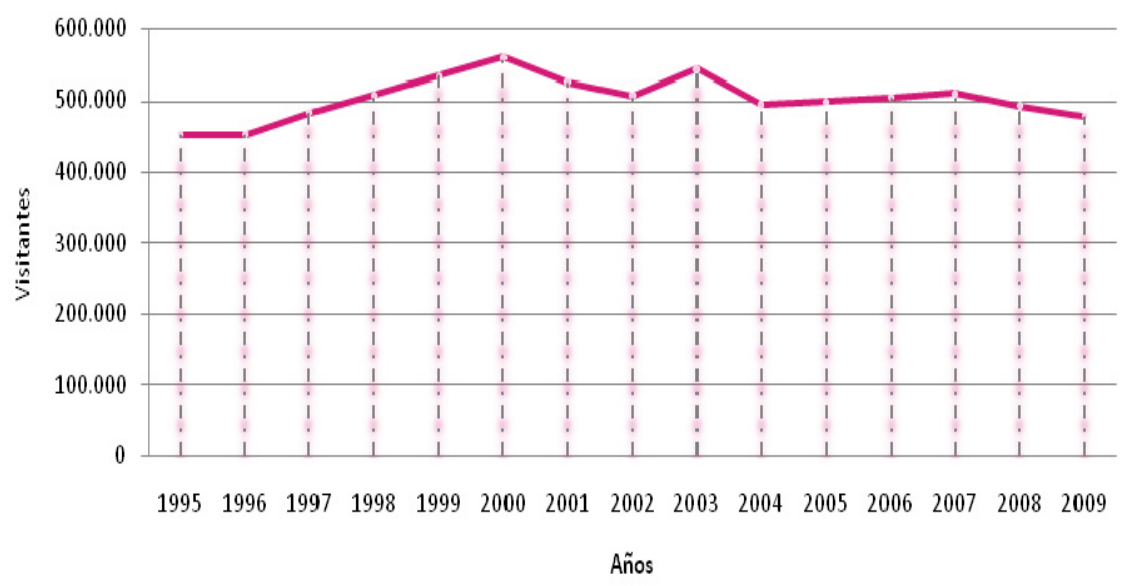

El flujo de visitantes, concentrado en abril-mayo y agosto-septiembreoctubre, las prácticas de utilización de los recursos patrimoniales, el ranking de visitantes a los monumentos y museos con entrada regulada y la focalización turística en pocos hitos y espacios evidencian, con claridad, que Segovia ha en- 
trado plenamente en un turismo de masas, algo que requiere de una ordenación y gestión del destino, más allá de los ámbitos estrictamente patrimoniales, para dar respuestas eficaces a los problemas planteados y cumplir adecuadamente los compromisos asumidos como ciudad Patrimonio de la Humanidad.

\section{A MODO DE CONCLUSIÓN: LUCES Y SOMBRAS EN UNA COMPLEJA E INTERDEPENDIENTE RELACIÓN ENTRE PA- TRIMONIO Y TURISMO.}

La equilibrada integración del turismo en los ámbitos patrimoniales y la plena incorporación del patrimonio como activo a los procesos de desarrollo sostenible, siendo una necesidad, no deja de ser, en buena medida, una utopía, al tratarse de un proceso complejo y lento cuya valoración depende, por un lado, de los parámetros y escala de valores con los que se analiza y, por otro, requiere actuar desde frentes diversos: urbanístico, patrimonial, cultural, social y turístico. En este sentido, más allá de las infraestructuras y equipamientos propiamente turísticos, de las mejoras urbanísticas o de las intervenciones puntuales, para aplicar realmente estrategias innovadoras y sostenibles hay que dotarse de instrumentos de gestión de naturaleza transversal, con fuerte capacidad coordinadora.

En una valoración de las políticas urbanas desarrolladas en las últimas décadas en las Ciudades Patrimonio de la Humanidad de Castilla y León todo parece evidenciar que se ha caminado con desequilibrios, primando, quizás en exceso, las dimensiones físico-arquitectónicas, por ser las que más fácilmente se visualizan, en detrimento de las sociales y funcionales. Una vez asentados los instrumentos necesarios para resolver los problemas físicos de la recuperación urbana, saltan algunas alarmas pues se comprueba que la recuperación integrada, estrechamente unida a la revitalización funcional y social, está encontrando bastantes dificultades, dominando procesos de simplificación funcional y social.

Hay un significativo contraste entre intervenciones singulares, fundamentalmente en hitos patrimoniales, frente a una tardía y débil actuación en los espacios residenciales de carácter popular. Las políticas de vivienda, tanto de promoción pública como de fomento de la rehabilitación privada, han tenido limitada incidencia. La recualificación del medio urbano, en los espacios equilibrados y dinámicos, ha arrastrado la rehabilitación del patrimonio edificado, no así en los espacios en situación más crítica.

En el marco de los cambios funcionales y sociales, la opción turística no puede plantearse, de forma generalizada, como alternativa única, solo en algunos casos y espacios actúa como variable determinante de la recuperación urbana. El declive demográfico y la pérdida de vida social, no tanto el turismo, son los 
que llevan aparejado la decadencia de las actividades económicas tradicionales, pequeño comercio, artesanía, servicios locales, etc. En los centros históricos de Ávila, Salamanca y Segovia se ha producido o se está produciendo una importante renovación del tejido comercial, en ocasiones con un excesivo protagonismo del sector turístico y, también, con frecuencia se ha depositado un exceso de confianza en el proyecto arquitectónico, vinculado a hoteles, museos, instalaciones administrativas, etc., sin una adecuada reflexión previa.

Ávila, Salamanca y Segovia han apostado por el turismo como pilar importante de su economía y con el impulso de los Planes de Excelencia Turística han renovado sus formas de verlo y gestionarlo, sin embargo, el aislamiento de la cuestión del conjunto patrimonial, una excesiva preocupación monumentalista y un tratamiento urbanístico poco atento a los cambios en las funcionalidades, especialmente las turísticas y culturales, evidencian debilidades en su conformación como destinos patrimoniales. De la interpretación crítica de las políticas urbanas aplicadas, turísticas, patrimoniales, sociales y urbanísticas, tienen que surgir ideas y proyectos para avanzar hacia una recuperación integrada donde la dimensión turística se integre en un proyecto urbano de base cultural. La actual crisis económica ofrece la oportunidad para un replanteamiento profundo de las políticas rehabilitadoras y para frenar o reconducir procesos que, en el caso de los destinos patrimoniales castellano-leoneses, implican riesgos de turistización o de excesiva tematización cultural. Los planes de gestión, reclamados por la UNESCO y en fase de desarrollo en Ávila y Salamanca, así como los proyectos instrumentados en Segovia, tienen el desafío de diseñar estrategias que contribuyan a solventar los problemas plantados a nivel patrimonial, funcional o social.

\section{BIBLIOGRAFÍA Y DOCUMENTACIÓN DE REFERENCIA}

Álvarez MorA, A. (1999): «El uso del espacio del centro histórico de Segovia en el marco de los programas de renovación y conservación de su contenido patrimonial». En CAmPesino, A. J. (coord.), Comercio, Turismo y Cambios Funcionales en las Ciudades Españolas Patrimonio de la Humanidad. Cáceres, Cámara de Comercio e Industria de Cáceres, 111-132.

Álvarez MorA, A. (2009): «Dinámicas y cambios urbanos en el Centro Histórico de Ávila». En, Soluciones Sostenibles para Ciudades Patrimonio Mundial. Ávila, Simposium Internacional. Fundación del Patrimonio Histórico de Castilla y León. (Ponencia inédita).

Ayuntamiento de Salamanca (2001): Plan Estratégico. Plan de Excelencia Turística de Salamanca. ICN-ARTEA S. L. Salamanca.

BRANDIS GARCÍA, D. y DEL RÍO LAFUENTE, I. (2008): «Turismo y medio ambiente urbano. Las experiencias de Ávila, Toledo y Salamanca». En TroitiÑo VinUESA, M. A. y García Marchante, J. S. (coords) Vivir las Ciudades Históricas: recuperación 
integrada y dinámica funcional. Cuenca, Ediciones Universidad de Castilla-La Mancha, 155-181.

BRito, M. (2009): Ciudades históricas como destinos patrimoniales. Una mirada comparada: España y Brasil. Sevilla, I.A.P.H. Consejería de Cultura. Junta de Andalucía.

Calle Vaquero, M. DE la (2006): «Intervención en destinos patrimoniales desde la perspectiva turística». En ASENJO, E. y CAMACHO, R. (coords): Las ciudades históricas del Mediterráneo. El sector turístico, dinamización cultural y nuevas tecnologías aplicadas al patrimonio cultural. Málaga, Junta de Andalucía-Universidad de Málaga, 193-214.

GARCÍA HERNÁNDEZ, M. (2004): «Ávila: planificación y gestión turística local en una ciudad patrimonio de la humanidad». En FonT SENTIAS, J. (coord): Casos de Turismo Cultural. De la planificación estratégica a la gestión del producto. Barcelona, Ariel, 413-441.

GARCÍA HERNÁNDEZ, M. (2007): «Entidades de planificación y gestión turística a escala local. El Caso de las Ciudades Patrimonio de la Humanidad de España». Cuadernos de Turismo, 20, 79-102.

HERNÁNDEZ SÁNCHEZ, A. I. (2010): «Del Atractivo al Posicionamiento. Los retos del destino turístico Salamanca». En AAVV, Soluciones Sostenibles para Ciudades Patrimonio Mundial. Valladolid, Fundación del Patrimonio Histórico de Castilla y León (en prensa).

HerRero Prieto, L. C. (2003): «El Turismo Cultural en Castilla y León: Un sector estratégico». En BlANCO, A. (ed.) Castilla y León, presente y futuro del Turismo. Madrid, Fundación Encuentro, 169-211.

Herrero Prieto, L. C. y OTROS (2004): Turismo Cultural e Impacto Económico de Salamanca 2002. Ciudad Europea de la Cultura. Madrid, Thomson-Civitas.

HoRTELANO MínguEZ, A. (2010): «Ávila: desarrollo urbano, conservación del patrimonio cultural y su uso turístico sostenible». En AAVV, Soluciones Sostenibles para Ciudades Patrimonio Mundial. Valladolid, Fundación del Patrimonio Histórico de Castilla y León (en prensa).

ICOMOS (2004): Ciudad Vieja de Segovia y su Acueducto. Informe Periódico sobre la Aplicación de la Convención sobre Patrimonio Mundial. Madrid, ICOMOS España.

ICN-ARTEA (2000): Anteproyecto Estratégico para el Plan de Excelencia Turística de Segovia. Pamplona (inédito).

INSTITUTO ANDALUZ DE PATRIMONIO HISTÓRICO (IAPH) (2009): El paisaje histórico urbano en las ciudades históricas patrimonio mundial. Indicadores para su conservación y gestión. Sevilla, Junta de Andalucía.

JunTA DE CASTILla y LEÓN (2008): Plan Estratégico de Turismo de Castilla y León 20092013. Valladolid, Consejería de Cultura y Turismo.

JunTa de CASTILla y LEÓn (2010): Boletín de Coyuntura Turística de Castilla y León. Resultados 2009. Valladolid, Consejería de Cultura y Turismo.

LAZZAROTTI, O. (2000): «Patrimoine et Tourisme: un Couple de la Mondialisation». Mappemonde, 57, 12-16.

MARTín BlANCO, M. A. (2010): «La conservación de la ciudad de Segovia. La experiencia del área de rehabilitación de la judería». En AAVV, Soluciones Sostenibles para 
Ciudades Patrimonio Mundial. Valladolid, Fundación del Patrimonio Histórico de Castilla y León (en prensa).

OCDE (2009): El Impacto de la Cultura en el Turismo. México, SECTUR.

SANZ, N. (2009): «Turismo, Cambio Cultural y Patrimonio Mundial». En TroitiÑo VINUESA, M. A. (ed.): Ciudades Patrimonio de la Humanidad: Patrimonio, Turismoy Recuperación Urbana. Sevilla, Universidad Internacional de Andalucía-Junta de Andalucía, 44-55.

Troitiño Torralba, L. (2009): Madrid y los Destinos Patrimoniales de su Región Turística. Madrid, Universidad Complutense de Madrid. Tesis doctoral (edición digital).

Troitiño Torralba, L. (2010): «Ciudades Patrimonio de la Humanidad de España: Dinámica Turística en Tiempos de Crisis (2000-2009)». En XII Coloquio del Grupo de Turismo, Ocio y Recreación, Madrid, AGE (comunicación).

TROITIÑO VINUESA, M. A. (1992): Cascos antiguos y centros históricos: problemas, politicas y dinámicas urbanas. Madrid, Ministerio de Obras Públicas y Transporte.

Troitiño VinUESA, M. A. (2000): «El Turismo cultural en las ciudades españolas Patrimonio de la Humanidad». En AAVV, Turismo Cultural: El Patrimonio Histórico como Fuente de Riqueza. Valladolid, Fundación del Patrimonio Histórico de Castilla y León, 111-138.

TroitiÑo VinUESA, M. A. (2008): «La catedral en el contexto turístico de la ciudad histórica». En Actas del Simposio Internacional: La Europa de las Catedrales. Conservación y Gestión. Valladolid, Fundación del Patrimonio Histórico de Castilla y León, 45-79.

Troitiño VINUESA, M. A. (2009a): «El papel del patrimonio en la sostenibilidad territorial, avanzando hacia nuevos modelos de desarrollo». En Observatorio de la Sostenibilidad en España-OSE, Patrimonio Natural, Cultural y Paisajístico. Claves para la Sostenibilidad Territorial. Madrid, Ministerio de Medio Ambiente y Medio Rural y Marino, 139-148.

Troitiño Vinuesa, M. A. (ed.) (2009b): Ciudades Patrimonio de la Humanidad: Patrimonio, Turismo y Recuperación Urbana. Sevilla, Universidad Internacional de Andalucía.

TROITIÑO VinUESA, M. A. (2009c): «El papel del turismo en la ciudad histórica en el marco conceptual de la Declaración de Viena. Funcionalidades emergentes y retos para la conservación y la gestión». En Instituto Andaluz de Patrimonio Histórico, El paisaje histórico urbano en las ciudades históricas patrimonio mundial. Indicadores para su conservación y gestión. Sevilla, Junta de Andalucía, 195-221.

TroitiÑo VinUESA, M. A. y OTROS (1998): «Ávila: Turismo y Realidad Urbana». Ávila, Cuadernos de la Escuela Regional de Turismo.

TROITIÑO VINUESA M. A. y OTROS (2003a): Salamanca 2002: Experiencia turística, flujos y perfil de los visitantes. Bases para la gestión turística de la ciudad. Madrid, Plan de Excelencia Turística de Salamanca-Universidad Complutense de Madrid (inédito).

Troitiño VinueSA, M. A. y OTROS (2003b): «Salamanca 2002: Repercusiones de la capitalidad cultural sobre la demanda turística de la ciudad». Pontevedra, VIII Congreso AECIT.(inédito). 
Troitiño VinuesA, M. A. y otros (2007): La Situación Turística del Grupo de Ciudades Patrimonio de la Humanidad de España. Bases para la Puesta en Marcha del Observatorio Turístico. León, Grupo de Ciudades Patrimonio de la Humanidad de España-Universidad Complutense de Madrid.

Troitiño Vinuesa, M. A. y otros (2009): Observatorio Turístico del Grupo de Ciudades Patrimonio de la Humanidad de España 2007. León, Grupo de Ciudades Patrimonio de la Humanidad de España-Universidad Complutense de Madrid.

Troitiño Vinuesa, M. A. y OTROs (2009): Observatorio Turístico de Segovia, $n^{o} 0$, Ayuntamiento de Segovia- Turismo de Segovia.

Troitiño VinuesA, M. A. y otros (2010): Observatorio Turístico del Grupo de Ciudades Patrimonio de la Humanidad de España. Informe 2008. Grupo de Ciudades Patrimonio de la Humanidad de España-Universidad Complutense de Madrid. Madrid. (Edición digital).

Troitiño Vinuesa, M. A.; CAlle, M. y García, M. (2002): Afluencia y perfil de los visitantes de la ciudad de Ávila. Temporada 2000-2001. Ávila, Plan de Excelencia Turística. Ayuntamiento de Ávila.

TroitiÑo VinUESA, M. A. y TroitiÑo TORRALBA, L. (2008): «Destinos patrimoniales y turismo: visitantes y uso turístico de la ciudad» En AIP: Uso Público e Interpretación del patrimonio natural y cultural. Sevilla, Asociación Interpretación del PatrimonioJunta de Andalucía, 106-151.

TroitiÑo VinUESA, M. A. y TROITIÑO TORRALBA, L. (2009): «Turismo cultural y destinos patrimoniales en España: situación actual y retos de futuro». En MONDEJAR, J. A. y Gómez, M. (coords), Turismo cultural en Ciudades Patrimonio de la Humanidad. Cuenca, Universidad de Castilla-La Mancha, 11-51

Troitiño Vinuesa, M. A. y Troitiño TorralbA, L. (2010): «Historic Cities and Tourism: Functional Dynamics and Urban Policy». The Open Urban Studies Journal, Vol. 3, 47-57 (en línea).

TuRISMO DE SEgOVIA (2008). Memoria, 2007. Segovia.

Velasco Romera, I. (2009): Paisaje e Intervención Urbana en Destinos Patrimoniales. Universidad Complutense de Madrid. Departamento de Geografia Humana. Trabajo de Investigación de Doctorado (inédito).

VILlAR CASTRO, J. (1999): «Ávila: un centro administrativo lastrado de tradición». En CAMPesino, A. J. (coord.), Comercio, Turismo y Cambios Funcionales en las Ciudades Españolas Patrimonio de la Humanidad. Cáceres, Cámara de Comercio e Industria de Cáceres, 61-80. 